\title{
PEOPLE PREFER SYSTEM 2 NUDGES (KIND OF)
}

\author{
CASS R. SUNSTEIN $\dagger$
}

\begin{abstract}
In the United States, the United Kingdom, Australia, and many other nations, those involved in law and policy have been exploring initiatives that preserve freedom of choice, or "nudges," informed by behavioral science and promoting important public policy goals, such as improved health and safety. But there is a large and insufficiently explored difference between System 1 nudges, which target or benefit from automatic processing, and System 2 nudges, which target or benefit from deliberative processing. Graphic warnings and default rules are System 1 nudges; statistical information and factual disclosures are System 2 nudges. On philosophical grounds, it might seem tempting to prefer System 2 nudges, on the assumption that they show greater respect for individual dignity and promote individual agency. A nationally representative survey in the United States finds evidence that, in important contexts, most people do prefer System 2 nudges. At the same time, that preference is not fixed and firm. If people are asked to assume that the System 1 nudge is significantly more effective, then many of them will shift to preferring the System 1 nudge. In a range of contexts, Republicans, Democrats, and independents show surprisingly similar responses. The survey findings and an accompanying normative analysis offer lessons for those involved in law and policy who are choosing between System 1 nudges and System 2 nudges.
\end{abstract}

Copyright (C) 2016 Cass R. Sunstein.

$\dagger \quad$ Robert Walmsley University Professor, Harvard University. I am grateful to Mary Schnoor for indispensable research assistance, especially with the statistical analyses here, and to Arevik Avedian, who helped organize and oversee the surveys here. Thanks also to Oren BarGill, Ralph Hertwig, Daniel Kahneman, Eric Posner, Lucia Reisch, and Glen Weyl for valuable comments on a previous draft, and to Bruce Ackerman, Christine Jolls, Jane Mansbridge, and Richard Thaler for helpful discussions; none of them should be held responsible for any errors. An early version of some of these results was presented at Yale Law School and at Yale's Institute for Social and Policy Studies, where I also received many helpful suggestions. Later versions were presented at the John F. Kennedy School of Government at Harvard University and the Max Planck Institute in Berlin, where I received superb suggestions as well. 


\section{TABLE OF CONTENTS}

Introduction 122

I. System 1 Nudges and System 2 Nudges 124

II. Four Standard Issues: Smoking, Savings, Pollution, and Water Conservation

A. Respondents in the Neutral Condition (Condition 1) .....135

B. Respondents Informed that the System 1 Nudge Is "Significantly More Effective" (Condition 2).

C. Respondents Informed that the System 1 Nudge Is "Significantly More Effective," with Additional Quantitative Information (Condition 3)

D. Respondents Informed that the System 2 Nudge Is "Significantly More Effective" (Condition 4).

E. Respondent Preferences by Partisan Affiliation ................141

III. Three Distinct Issues: Voting, Children, and Abortion ..............144

A. Testing Preferences as Between the System 1 and System 2 Nudge in the Context of the Three Distinctive Issues .....145

B. General Results for the Preference as Between the System 1 and System 2 Nudge in the Context of Three Distinctive Issues 146

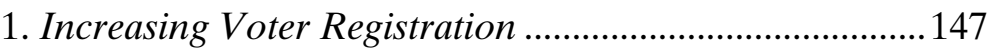

2. Combatting Childhood Obesity ........................................147

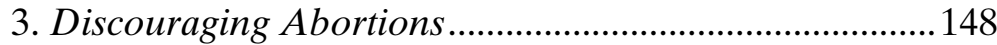

C. Respondent Preferences by Partisan Affiliation ...............149

IV. Digging Deeper into the Findings: Follow-Up Studies ................151

A. Testing Preferences with a Within-Subjects Design .........152

B. Testing Beliefs About Effectiveness, as Opposed to Preference

C. Comparing the Assumptions that the System 1 Nudge Is "Significantly More Effective" or "Dramatically More Effective" 157

D. Testing Preferences with an "Either or Both" Option ....159

V. Popular Opinion, Law, and Public Policy. 160

Conclusion. 165

\section{INTRODUCTION}

In numerous nations, those involved in law and policy have been exploring policy initiatives that preserve freedom of choice, or "nudges," informed by behavioral economics and psychology and 
meant to promote important goals, such as improved health and safety. ${ }^{1}$ But there is a large and insufficiently explored difference between System 1 nudges, which are not educative and which target or benefit from automatic processing, and System 2 nudges, which are educative and target or benefit from deliberative processing. Graphic warnings and default rules count as System 1 nudges; statistical information and factual disclosures count as System 2 nudges.

On philosophical grounds, it is tempting to prefer System 2 nudges, on the assumption that they show greater respect for individual autonomy and dignity and promote individual agency. But it is also possible to prefer System 1 nudges, on the ground that they are likely to be cheaper and more effective, and also because they promote autonomy in their own way, by allowing people to conserve scarce cognitive resources and to devote attention to their largest concerns. For example, automatic enrollment in sensible savings plans might be preferable to financial education-or vice versa. Any judgment between System 1 and System 2 nudges would seem to require judgments about social welfare and individual autonomy, and the extent to which one or another nudge will promote them.

A nationally representative survey in the United States finds evidence that, in important contexts in law and policy, a majority does prefer System 2 nudges. At the same time, that preference is not fixed and firm. If people are asked to assume that the System 1 nudge is significantly more effective, then many of them will shift to preferring the System 1 nudge. In a range of contexts, Republicans, Democrats, and independents show surprisingly similar responses.

The survey findings fit with an analysis of a basic principle, which suggests that on grounds of welfare and autonomy, the choice between the two kinds of nudges is not self-evident. A great deal depends on context. In some settings, a System 1 nudge will promote social welfare and will not compromise autonomy in any way, and in some settings, a System 2 nudge is better on welfare grounds and will best promote autonomy. The survey findings, and the analysis, offer concrete lessons for those involved in law and policy who are choosing between System 1 nudges and System 2 nudges.

1. See generally DAVID HALPERN, INSIDE THE NUDGE UNIT (2015) (recounting the efforts of the United Kingdom's Behavioural Insights Team, nicknamed the "Nudge Unit"); RHYS JONES, JESSICA PYKETT \& MARK WHITEHEAD, CHANGING BEHAVIOURS: ON THE RISE OF THE PSYCHOLOGICAL STATE (2013) (analyzing the emergence of this trend); CASS R. SUNSTEIN, SIMPLER (2013) (discussing this approach in the context of its application by the Obama Administration). 


\section{SYSTEM 1 NudGES AND SYSTEM 2 NUDGES}

Nudges are interventions that steer people in particular directions but also allow them to go their own way. ${ }^{2} \mathrm{~A}$ reminder is a nudge; so is a warning. A GPS device nudges; a default rule nudges. Disclosure of relevant information (for example, about the risks of smoking or the costs of borrowing) counts as a nudge. A recommendation is a nudge. "Save More Tomorrow" plans, which allow employees to sign up to give some portion of their future earnings to pension programs, are nudges. ${ }^{3}$ The same is true of "Give More Tomorrow" plans, which allow employees to decide to give some portion of their future earnings to charity. ${ }^{4}$

In many domains of law and policy, nudges are easy to find, whether or not they go by that name. ${ }^{5}$ In an increasing number of nations, including the United States and the United Kingdom, behavioral economics and cognitive psychology are being used to reorient law and policy in numerous areas, including savings, organ donation, energy, the environment, smoking, poverty, crime, voting behavior, and health. ${ }^{6}$

In terms of law and public policy, it is helpful to distinguish between educative and noneducative nudges. Educative nudges include disclosure requirements, reminders, and warnings, which are specifically designed to increase people's own powers of agency-

2. See Richard H. Thaler \& Cass R. Sunstein, Nudge: Improving Decisions ABOUt HEALTH, WEALTH, AND HAPPINESS 6 (2008) (defining and exploring choice-preserving approaches).

3. See Richard H. Thaler, Misbehaving: The Making OF BeHaVIORAl ECONOMICS 309-22 (2015).

4. See generally Anna Breman, Give More Tomorrow: Two Field Experiments on Altruism and Intertemporal Choice, 95 J. PUB. ECON. 1349 (2011) (showing significant increases in giving when Give More Tomorrow programs are implemented).

5. The most important examples are default rules, on which the literature is voluminous. For a classic discussion, see generally Ian Ayres \& Robert Gertner, Filling Gaps in Incomplete Contracts: An Economic Theory of Default Rules, 99 YALE L.J. 87 (1989) (analyzing how decisionmakers should set default rules). On nudging that is harmful, see generally GEORGE A. AKERLOF \& ROBERT J. SHILlER, PHISHING FOR PHOOLS: THE ECONOMICS OF MANIPULATION AND DECEPTION (2015) (exploring how markets reward certain kinds of manipulation); OREN BAR-GILL, SEDUCTION BY CONTRACT (2012) (exploring how markets reward companies that exploit behavioral biases).

6. See supra note 1. For an important executive order on the uses of behavioral science, see Using Behavioral Science Insights to Better Serve the American People, 80 Fed. Reg. 56,365 (Sept. 15, 2015), https://www.gpo.gov/fdsys/pkg/FR-2015-09-18/pdf/2015-23630.pdf [https:// perma.cc/BEK3-P9L8] (directing agencies to use behavioral science in engaging with the American people). 
perhaps by augmenting their knowledge and their capacities, perhaps by making relevant facts salient. Educative nudges can promote welfare by enabling people to make choices that increase their wellbeing. In addition, educative nudges can easily fit within those aspects of the liberal political tradition that emphasize agency and autonomy. By adding to people's stock of knowledge, they can help them to be better choosers.

Noneducative nudges include default rules and strategic decisions about how items are ordered (as on a menu or at a cafeteria); these are designed to preserve freedom of choice without necessarily increasing individual agency. Noneducative nudges may well increase welfare in the same way that GPS devices do (because they make it so much easier to navigate); such nudges might also be welcome because they impose few demands, in terms of time or attention, on those whom they are aimed to benefit. In that respect, noneducative nudges might promote autonomy in addition to welfare.

Within behavioral science, some people have found it helpful to distinguish between two families of cognitive operations in the human mind: System 1, which is fast, automatic, and intuitive, and System 2, which is slow, calculative, and deliberative. ${ }^{8}$ When people recognize a smiling face, add three plus three, or know how to get to their bathroom in the middle of the night, System 1 is at work. When people first learn to drive, when they multiply 563 times 322, or when they choose a medical plan among several hard-to-distinguish alternatives, they must rely on System 2.

System 1 can and often does get things right. ${ }^{9}$ As Daniel Kahneman and Shane Frederick write, "Although System 1 is more

7. See generally JosePh RAZ, THE MORALITY OF FREEDOM (1986) (describing a liberal conception of freedom and autonomy).

8. See generally DANIEl KAHNEMAN, THINKING, FAST AND Slow (2011) (describing and analyzing this distinction and its impact). The idea of two systems is controversial, and it is reasonable to ask what, exactly, the idea is meant to capture. For example, something very different from a two-systems account is offered in Elizabeth A. Phelps, Karolina M. Lempert \& Peter Sokol-Hessner, Emotion and Decision Making: Multiple Modulatory Neural Circuits, 37 ANN. ReV. NeUROSCIENCE 263, 281-82 (2014) (suggesting that multiple, not dual, systems underlie decisionmaking). Following Kahneman, I understand the idea as a useful fiction, not referring to "systems in the standard sense of entities with interacting aspects or parts." KAHNEMAN, supra, at 29. For those who reject the terminology, or are skeptical of it, it might be helpful simply to distinguish between noneducative and educative nudges, and to see the surveys here as asking when people prefer one or the other.

9. See generally Daniel Kahneman \& Gary Klein, Conditions for Intuitive Expertise: A Failure to Disagree, 64 AM. PSYCHOLOGIST 515 (2009) (showing that those with apparently 
primitive than System 2, it is not necessarily less capable." ${ }^{10}$ Through fast and frugal heuristics, people can perform exceedingly well. ${ }^{11}$ Any professional athlete or musician has an educated System 1; Serena Williams knows what shot to hit in an instant, and Taylor Swift has no difficulty remembering how to play her songs. As a result of years of practice, an experienced lawyer, judge, doctor, or engineer has a welltrained System 1, and trained intuitions are often on the mark. ${ }^{12}$ At the same time, System 2 is hardly unerring. On multiplication problems, or in choosing among health-care plans, people often make mistakes, even if they are trying very hard. ${ }^{13}$

Nonetheless, System 1 is distinctly associated with identifiable behavioral biases,${ }^{14}$ producing a wide range of problems for policy and law. ${ }^{15}$ People sometimes show "present bias," focusing on the shortterm and downplaying the future. ${ }^{16}$ Most people tend to be unrealistically optimistic. ${ }^{17}$ People use heuristics-or mental shortcuts - that usually work well, but that sometimes lead them in

different perspectives on intuitions, or System 1, agree that educated and trained people often make excellent, rapid decisions).

10. Daniel Kahneman \& Shane Frederick, Representativeness Revisited: Attribute Substitution in Intuitive Judgment, in HeURISTICS AND BIASES: THE PSYCHOLOGY OF INTUITIVE JUDGMENT 49, 51 (Thomas Gilovich et al. eds., 2002).

11. See generally Gerd GigerenZer, Peter M. TOdD \& ABC RESEARCH GrP., SimPle HEURISTICS THAT MAKE Us SMART (1999) (discussing the use of intuitive heuristics to make quick but effective decisions); GERD GIGERENZER, SIMPLY RATIONAL (2015) (same).

12. See generally Gary Klein, Sources of Power: How People MaKe Decisions (1998) (exploring how individuals with on-the-job experience make intuitive decisions in difficult circumstances).

13. See generally Eric J. Johnson, Ran Hassin, Tom Baker, Allison T. Bajger \& Galen Treuer, Can Consumers Make Affordable Care Affordable? The Value of Choice Architecture, PLOS ONE (Dec. 18, 2013), http://journals.plos.org/plosone/article/asset?id=10.1371\%2Fjournal. pone.0081521.pdf [https://perma.cc/WPX4-2QS8] (concluding that individuals using online exchanges are not very good at choosing the most cost-effective health insurance plan).

14. See KAHNEMAN, supra note 8, at 7; Kahneman \& Frederick, supra note 10, at 53-54. For catalogues of relevant findings, see generally BEHAVIORAL ECONOMICS OF PREFERENCES, CHOICES, AND HAPPINESS (Shinsuke Ikeda et al. eds., 2015) (cataloguing a wide range of biases); COGNITIVE ILLUSIONS: A HANDBOOK ON FALLACIES AND BIASES IN THINKING, JUDGEMENT AND MEMORY (Rüdiger F. Pohl ed., 2004) (same).

15. For a range of demonstrations, see generally THE BeHAVIORAL Foundations of PUBLIC POLICY (Eldar Shafir ed., 2013).

16. For references and discussion, see Cass R. Sunstein, The Storrs Lectures: Behavioral Economics and Paternalism, 122 YALE L.J. 1826, 1842-52 (2013) (discussing present bias and related biases).

17. See generally Tali Sharot, The Optimism Bias: A Tour of the Irrationally POSITIVE BRAIN (2011) (exploring the human tendency to be unrealistically optimistic). 
unfortunate directions. ${ }^{18}$ With respect to probability, people's intuitions may go badly wrong, in the sense that they produce serious mistakes, including life-altering ones. ${ }^{19}$ To be sure, our intuitions are both adequate and helpful in the situations in which we ordinarily find ourselves..$^{20}$ But there is no question that intuitions can badly misfire, ${ }^{21}$ and that good nudges, and good choice architecture, will often provide indispensable assistance, by helping people move in directions that they themselves prefer. ${ }^{22}$ The regulatory and legal systems often respond. ${ }^{23}$

Educative nudges, offered by government agencies, should be seen as attempts to strengthen the hand of System 2 by improving the

18. See KAHNEMAN, supra note 8 , at 7 .

19. For a powerful demonstration, see Daniel L. Chen, Tobias J. Moskowitz \& Kelly Shue, Decision-Making Under the Gambler's Fallacy: Evidence from Asylum Judges, Loan Officers, and Baseball Umpires 12-26 (Jan. 12, 2016) (unpublished manuscript), http://papers.ssrn.com/ sol3/papers.cfm?abstract_id=2538147 [https://perma.cc/W8H2-STE2] (showing that decisionmakers often try to make sure that in small samples, the percentage of favorable and unfavorable outcomes tracks what would be observed in large samples).

20. This position is vigorously defended in GIGERENZER ET AL., supra note 11 , at 6 . For a broader discussion, see generally MARK KELMAN, THE HEURISTICS DEBATE (2011) (exploring apparently competing positions about whether heuristics produce systematic biases or are instead essentially accurate). In my view, the outcome of this occasionally heated debate within psychology does not have strong implications for law and policy. Everyone agrees that heuristics generally work well; that is why they exist. On that count, there is no opposition between the supposedly competing sides. Everyone agrees that heuristics are generally fast and frugal. Everyone also agrees that in important cases, boundedly rational people make mistakes. Everyone should also agree that in important cases, excellent (in the sense of useful and generally accurate) heuristics produce errors. When they make mistakes, some kind of nudge, or an improvement in choice architecture, might help. To be sure, the best nudge may or may not involve education or some kind of "boost." See generally Ralph Hertwig \& M.D. Ryall, Nudge vs. Boost: Agency Dynamics Under "Libertarian Paternalism" (Jan. 1, 2016) (unpublished manuscript), http://papers.ssrn.com/sol3/papers.cfm?abstract_id=2711166 [https://perma.cc/ W8H2-STE2] (defining boosts and exploring some of their potential advantages).

21. In the context of household finance, see generally John Y. Campbell, Restoring Rational Choice: The Challenge of Consumer Financial Regulation, 106 AM. ECON. REV. (PAPERS \& PROC.) 1 (2016) (cataloguing household errors and calling for various forms of intervention, including mandates, to correct them).

22. For a powerful demonstration, see Raj Chetty, John N. Friedman, Søren Leth-Petersen, Torben Nielsen \& Tore Olsen, Active vs. Passive Decisions and Crowdout in Retirement Savings Accounts: Evidence from Denmark 40-43 (Nat'l Bureau of Econ. Research, Working Paper No. 18565, 2012), http://www.nber.org/papers/w18565 [https://perma.cc/9TDQ-Y63Z] (finding large effects from automatic enrollment in savings plans). For overviews, see generally HALPERN, supra note 6 (outlining initiatives of the Behavioural Insights Team in the United Kingdom); Raj Chetty, Behavioral Economics and Public Policy: A Pragmatic Perspective, 105 AM. ECON. REV. 1 (2015) (suggesting an assortment of policies informed by behavioral economics).

23. For recent illustrations, see generally HALPERN, supra note 1; JONES ET AL., supra note 1. 
role of deliberation and people's considered judgments. ${ }^{24}$ The most obvious example is disclosure of relevant information. ${ }^{25}$ Some kinds of nudges, sometimes described as "boosts," attempt to improve people's capacity to make choices for themselves, for example by improving statistical literacy. ${ }^{26}$

Noneducative nudges are designed to appeal to, or to enlist, System $1 .{ }^{27}$ Graphic health warnings can be seen as an example, at least if they are not understood as having the purpose or effect of education. $^{28} \mathrm{We}$ might distinguish between System 2 disclosures, designed simply to give people factual information and ask them to process it, and System 1 disclosures, designed to work on the automatic system (for example, by inculcating fear or hope). ${ }^{29}$ Some nudges do not appeal to System 1, strictly speaking, but turn out to work because of their operation-as, for example, where default rules have large effects in part because of the power of inertia ${ }^{30}$ or where the ordering

24. For many examples, see generally SUNSTEIN, supra note 1 (exploring educative nudges used by the U.S. government, including labels of various kinds); Till Grüne-Yanoff \& Ralph Hertwig, Nudge Versus Boost: How Coherent Are Policy and Theory?, 26 Minds \& MACHINES 149 (2016) (discussing the idea of "boosts" and exploring some of the reasons that they might be preferred).

25. The Credit Card Accountability Responsibility and Disclosure (CARD) Act of 2009 contains several examples. Credit Card Accountability Responsibility and Disclosure Act of 2009, Pub. L. No. 111-24, 123 Stat. 1734 (codified as amended in scattered sections of 15 U.S.C.). They are outlined, and their effects are discussed, in Sumit Agarwal, Souphala Chomsisengphet, Neale Mahoney \& Johannes Stroebel, Regulating Consumer Financial Products: Evidence from Credit Cards (Aug. 2014) (unpublished manuscript), http://papers.ssrn.com/sol3/ papers.cfm?abstract_ $\mathrm{id}=2330942$ [https://perma.cc/6CTP-AYTP] (finding that the CARD Act has saved consumers over $\$ 12$ billion annually). See generally SUNSTEIN, supra note 6 (offering a variety of illustrations).

26. See generally Grüne-Yanoff \& Hertwig, supra note 24 (exploring the value of interventions that boost people's capacities).

27. RiccARdo Rebonato, TAKing Liberties 6 (2012). Rebonato actually defines libertarian paternalism in a way that fits with what I am calling System 1 nudges, seeing it as "the set of interventions aimed at overcoming the unavoidable cognitive biases and decisional inadequacies of an individual by exploiting them." Id. In the same vein, see Grüne-Yanoff \& Hertwig, supra note 24, at 149-51.

28. R.J. Reynolds Tobacco Co. v. FDA, 823 F. Supp. 2d 36, 47 (D.D.C. 2011), aff'd, 696 F.3d 1205 (D.C. Cir. 2012). For an excellent discussion, see generally Christine Jolls, Product Warnings, Debiasing, and Free Speech: The Case of Tobacco Regulation, 169 J. InSTITUTIONAL \& THEORETICAL ECON. 53 (2013) (finding that graphic warnings can actually make people better informed).

29. See Ryan Bubb, TMI? Why the Optimal Architecture of Disclosure Remains TBD, 113 MICH. L. REV. 1021, 1022-25 (2015) (noting differences between System 1 disclosures and System 2 disclosures and suggesting that the former might be more effective).

30. See Johnson et al., supra note 13, at 5 (exploring the power of default rules and the role of inertia). 
of items on a menu affects what people choose, because of the selective nature of attention. ${ }^{31}$ Nudges of this kind can be seen as "exploiting" the operations of System $1,{ }^{32}$ though it would be more neutral to say that they take account of those operations, acknowledging that some form of choice architecture, likely affecting System 1, is inevitable. ${ }^{33}$

As I understand them here, System 2 nudges are specifically designed to increase people's capacity to exercise their own agency. On ethical and other grounds, they might seem better for that reason. ${ }^{34}$ As Jeremy Waldron writes, "I wish, though, that I could be made a better chooser rather than having someone on high take advantage (even for my own benefit) of my current thoughtlessness and my shabby intuitions." $" 35$

In the abstract, Waldron's wish is an honorable one,$^{36}$ and some nudges are specifically designed to fulfill it. But as a matter of principle, the challenge arises when it is costly and difficult to make people better

31. See Eran Dayan \& Maya Bar-Hillel, Nudge to Nobesity II: Menu Positions Influence Food Orders, 6 JudGMENT \& DECISION MAKING 333, 333 (2011) (demonstrating effects of position on a menu); Daniel R. Feenberg, Ina Ganguli, Patrick Gaule \& Jonathan Gruber, It's Good To Be First: Order Bias in Reading and Citing NBER Working Papers (Nat'l Bureau of Econ. Research, Working Paper No. 21141, 2015), http://www.nber.org/papers/w21141 [https://perma.cc/K2XU-WY5K] (showing that people are more likely to read and cite academic papers that come first in a list).

32. See REBONATO, supra note 27, at 6 (suggesting that nudges exploit behavioral biases).

33. For a sustained argument that because of market pressures, System 1 nudges from the private sector are endemic in a market economy, see generally AKERLOF \& SHILLER, supra note 5 (discussing how market pressures lead sellers to exploit ignorance and cognitive biases).

It is true and important that all System 1 nudges are not the same, and that people might reasonably distinguish among them. It would be possible to be skeptical about graphic health warnings and to approve of automatic enrollment, and vice versa. One might think, for example, that graphic warnings do not treat people with sufficient respect and that automatic enrollment is a valuable time-saver, or instead think that graphic warnings are informative and unobjectionable, see Jolls, supra note 28, at 57-58, and that automatic enrollment exploits people's tendency toward inertia. It is also true that System 2 nudges might have meaningful differences; a simplified disclosure could be better or worse than a more complicated one.

I am bracketing these various complexities here. Further work might test whether particular kinds of System 1 nudges attract particular support or disapproval and exactly why. Some preliminary evidence on this count can generally be found in Janice Y. Jung \& Barbara A. Mellers, American Attitudes Toward Nudges, 11 Judgment \& DeCision MAKING 62 (2016) (finding general support for nudges) and also in CASS R. SUNSTEIN, THE ETHICS OF INFLUENCE (2016) (same).

34. This idea is called into question by the illuminating discussion in Andrés Moles, Nudging for Liberals, 41 SOC. THEORY \& PRAC. 644 (2015).

35. Jeremy Waldron, It's All for Your Own Good, N.Y. REV. BooKs (Oct. 9, 2014), http://www.nybooks.com/articles/archives/2014/oct/09/cass-sunstein-its-all-your-own-good [https://perma.cc/4MXL-ZYN2].

36. REBONATO, supra note 27 , is in a similar vein. 
choosers - and when the net benefits of a System 1 nudge are far higher than the net benefits of a System 2 nudge. ${ }^{37}$ System 1 nudges, such as automatic enrollment, make life much simpler, and that is no small gain. ${ }^{38}$ There is also evidence that System 2 nudges can affect beliefs without affecting behavior, and that System 1 nudges can be more effective in altering what people actually do. ${ }^{39}$ The choice between System 1 nudges and System 2 nudges raises pervasive and fundamental questions about agency, freedom, and welfare.

My primary goal in this Article is to report the results of a nationally representative survey designed to elicit people's preferences as between System 1 nudges and System 2 nudges in diverse contexts. ${ }^{40}$ Administered by Survey Sampling International, the survey included more than 2,800 Americans, who were paid for their participation. As we shall see, I also conducted a series of clarifying surveys on Amazon Mechanical Turk ${ }^{41}$ but my emphasis will be on the nationally representative survey. In brief, seven different groups, each consisting of more than four hundred people, were asked to register their

37. Lauren E. Willis, The Financial Education Fallacy, 101 AM. ECON. REV. 429, 430 (2011) (arguing that financial education does not work and that other approaches, such as automatic enrollment, are better). See generally Grüne-Yanoff \& Hertwig, supra note 24 (identifying some limits and costs of nudges).

38. See generally SendHIL Mullainathan \& Eldar SHAFIR, ScARCITY (2013) (emphasizing that poverty, hunger, loneliness, and time-management problems create what they call cognitive "scarcity," creating a bandwidth problem that can impair decisions).

39. See Sandro Ambuehl, B. Douglas Bernheim \& Annamaria Lusardi, The Effect of Financial Education on the Quality of Decision Making 5-6 (Nat'l Bureau of Econ. Research, Working Paper No. 20618, 2014), http://www.nber.org/papers/w20618 [https://perma.cc/H8YCDQF5] (exploring the mixed effects of financial education on decision making).

40. Three other studies with different designs have explored this question. See generally Gidon Felsen, Noah Castelo \& Peter B. Reiner, Decisional Enhancement and Autonomy: Public Attitudes Toward Overt and Covert Nudges, 8 JudgMEnT \& DeCISION MAKING 202 (2013) (testing people's attitude toward employment prospects, and finding generally high levels of approval of System 2 nudges); Jung \& Mellers, supra note 33 (finding that, on bounded scales, people generally prefer System 2 nudges); Ayala Arad \& Ariel Rubinstein, The People's Perspective on Libertarian-Paternalistic Policies (July 2015) (unpublished manuscript), http://www.tau.ac.il/ aradayal/LP.pdf [https://perma.cc/C95Y-MKLD] (finding evidence of "reactance" against System 1 nudges and some inclination to prefer System 2 nudges). The findings in this Article are broadly compatible with those in these earlier papers. At the same time, the present survey is (so far as I am aware) the first to ask people to make an extended series of direct choices between System 1 and System 2 nudges (though Arad and Rubinstein do ask several questions that provide some evidence on that issue).

41. The sample on Amazon Mechanical Turk is not nationally representative. For discussion, see Connor Huff \& Dustin Tingley, "Who Are These People?” Evaluating the Demographic Characteristics and Political Preferences of MTurk Survey Respondents, RES. \& POL., July-Sept. 2015, at 1 . Note that in my surveys, the results on Amazon Mechanical Turk are quite close to the results in the nationally representative survey, where the same questions were asked. 
preferences as between System 1 and System 2 nudges. Respondents were asked to choose between a System 1 nudge, which involved either a graphic warning or a default rule, and a System 2 nudge, which involved some form of education.

The central question was whether people preferred educative or noneducative nudges in a pairwise comparison on each topic. Four of the pairs involved areas in which nudges have often been used as policy tools: savings, smoking, clean energy, and water conservation. ${ }^{42}$ In many ways, these pairs, which serve as the focus of Part II, can be seen as standard, illustrating as they do dilemmas that can be found in multiple domains. Three other pairs, which serve as the focus for Part III, involved areas that raise highly distinctive issues and concerns: voter registration, childhood obesity, and abortion. ${ }^{43}$

With respect to the four standard issues, the first finding is that, in a neutral condition in which participants received no information about the effectiveness of System 1 or System 2 nudges, a majority of respondents preferred the System 2 nudge. Notably, however, a strong minority-between 26 percent and 45 percent-favored System 1 nudges. In the neutral condition, two of the four issues produced no significant differences among Democrats, Republicans, and independents. And while two of the issues did produce such differences, with a higher percentage of Democrats favoring System 1 nudges, the differences were relatively small.

The second finding is that when people were asked to assume that System 1 nudges were "significantly more effective," many of the respondents shifted their preference to such nudges - but the shift was relatively modest, usually in the vicinity of about 12 percentage points. The third finding is surprising: when people were presented with specific numbers offering a quantitative demonstration that System 1 nudges were more effective, the shift in the direction of System 1 nudges was essentially the same in magnitude. The fourth and final finding is also surprising: when people were asked to assume that

42. I borrow the water conservation example from Jung \& Mellers, supra note 33, at 67.

43. Note that the various questions asked people abstractly about policies; they did not personalize those policies by suggesting that the policies would apply to "you." There is some intriguing evidence that when people see an arguably paternalistic nudge as applying to them personally, they are less likely to support it. See generally James F.M. Cornwell \& David H. Krantz, Public Policy for Thee, but Not for Me: Varying the Grammatical Person of Public Policy Justifications Influences Their Support, 9 JUDGMENT \& DECISION MAKING 433 (2014) (showing lower levels of support for nudges directed at "you"). An important paper, however, does not find any such effect in general. See Jung \& Mellers, supra note 33, at 70-71 (finding no such effect). 
System 2 nudges were "significantly more effective," there was no shift in the direction of those nudges. This is a mystery, and I will attempt to explain it.

The most obvious interpretation of these findings is that in important contexts, most participants want to protect and promote people's agency, so they will favor System 2 nudges ${ }^{44}$ - but many also care about effectiveness, and so will turn to System 1 nudges if the evidence shows that they are significantly better. At the same time, there is significant heterogeneity within the American population. Many people prefer System 1 nudges, perhaps on the ground that they are more effective, perhaps on the ground that they make life simpler and easier. Some people appear not to have any abstract preference as between System 1 nudges and System 2 nudges; they appear to care only about effectiveness. ${ }^{45}$ By contrast, some people have a strong preference for System 2 nudges, and will require compelling evidence of superior effectiveness to switch to favoring System 1 nudges. Because a significant number of Americans show no inclination to prefer System 1 nudges even when asked to assume that they are clearly more effective, we can safely say that some segment of the population would demand very powerful evidence to favor System 1 nudges - and perhaps no evidence would be sufficient. ${ }^{46}$ I shall offer some concrete evidence to this effect. ${ }^{47}$

With respect to the three distinctive issues-increasing voter registration, combatting childhood obesity, and discouraging abortions - the patterns are illuminatingly different. In the neutral condition, a majority of respondents did not favor System 2 nudges for the first two issues. On the contrary, automatic voter registration had clear majority support, and for childhood obesity, a majority deemed

44. There is a relationship here with the finding of a "control premium" described generally in Sebastian Bobadilla-Suarez, Cass R. Sunstein \& Tali Sharot, Are Choosers Losers? The Propensity to Under-Delegate in the Face of Potential Gains and Losses (Feb. 15, 2016) (unpublished manuscript), http://papers.ssrn.com/sol3/papers.cfm?abstract_id=2733142 [https:// perma.cc/G4GB-NRPY] (finding that people will sacrifice money to maintain control, even when their own information suggests that it is in their interest to delegate).

45. See Arad \& Rubinstein, supra note 40, at 18-19 (finding that many people fall into this category for certain nudges).

46. Note, however, that most Americans do support System 1 nudges, as for example in the context of graphic warnings for cigarettes and graphic campaigns to deter distracted driving and childhood obesity. See SunsteIn, supra note 33 , at 132 . The point here is that in a pairwise comparison, Americans tend to prefer System 2 nudges.

47. See infra Table 17. 
cafeteria design ${ }^{48}$ to be preferable to parental education. Asking people to assume the significantly greater effectiveness of the System 1 nudge does increase the level of support, but it is high even without that information. The best explanations for the preference for System 1 nudges involve people's judgments about the protection of the franchise (arguing in favor of automatic registration) and the protection of children (favoring cafeteria design).

With respect to reducing the number of abortions, a majority of respondents consistently favored System 2 nudges, and that preference did not shift when people were asked to assume that System 1 nudges were more effective-undoubtedly because of a belief, on the part of many, that it is not appropriate for public officials to appeal to System 1 nudges to discourage women from making their own choices. Notably, Republicans, Democrats, and independents all favored System 2 nudges in the abortion setting, although in most conditions, the level of support for System 1 nudges was significantly lower among Democrats. The sharp distinction between majority approval of a System 1 nudge for increasing voter registration and majority approval of a System 2 nudge for discouraging abortions attests to the importance of people's judgments about whether a right is at stakeand whether a nudge is promoting or undermining it.

The findings from the seven surveyed issues support a variety of conclusions. In important areas of regulatory policy, including environmental protection, savings, and health, a majority of Americans will prefer System 2 nudges to System 1 nudges, but there is likely to be significant division on that issue. If System 1 nudges are shown to be more effective, there will be an increase in preference for those nudges, but the increase will not be as dramatic as might be anticipated, apparently because some people put a high premium on personal agency. Insofar as children are involved, System 1 nudges will be more welcome, and the same is true if System 1 nudges facilitate people's ability to enjoy something that qualifies as a right. If, on the other hand, any kind of nudge is compromising what people regard as a right, it will be rejected, and a System 2 nudge will be preferred because it shows greater respect for individual agency.

In important respects, the survey findings are consistent with what emerges from a more sustained analysis of the normative issues; I sketch the central ingredients of that analysis here. Both the findings

48. For the best discussion, see generally BRIAN WANSINK, SLIM BY DESIGN (2014) (exploring the effects of choice architecture in producing obesity). 
and the analysis bear on a variety of issues in law and policy. They suggest identifiable reasons to prefer System 2 nudges, such as disclosure of statistical information or some kind of education. But they also suggest that in many contexts, System 1 nudges such as default rules are preferable, certainly if the goal is to increase welfare. ${ }^{49}$ One reason is that System 1 nudges may be more effective; a more important reason is that they might have higher net benefits, and thus be the best way to increase welfare. ${ }^{50}$ It might be tempting to think that System 1 nudges are objectionable because they reduce autonomy, but as we shall see, such nudges may actually increase autonomy. This is not least because they may make people rights-holders by default (as in the case of automatic voter registration), and also because they leave people with the time and bandwidth to focus on their most fundamental concerns.

As we shall also see, System 1 might be inclined to favor System 2 nudges: that is, people may well have an immediate, automatic sense that educative nudges are better. On this point, System 2 will frequently concur. But for many rights and interests, System 2 will ultimately decide that System 1 nudges are best on both welfare and autonomy grounds.

\section{FOUR STANDARD ISSUES: SMOKING, SAVINGS, POLLUTION, AND WATER CONSERVATION}

My goal in this Part is to explore the principal survey itself. Let us begin with some additional remarks about methodology.

The first four questions asked people to say whether they preferred a System 1 or System 2 nudge in the context of some familiar interventions in law and policy. ${ }^{51} \mathrm{I}$ describe these issues as "standard" because they come up frequently in discussions of nudges and

49. Bubb, supra note 29, at 1026; Willis, supra note 37, at 432 (arguing that default rules are preferable to financial education).

50. I am bracketing the question of how best to define that contested concept. See generally MATTHEW D. AdLER, WELFARE AND FAIR DisTRIBUTION: BEYOND COST-BENEFIT ANALYSIS (2012) (exploring the idea of social welfare in great detail.)

51. See generally Felix Ebeling \& Sebastian Lotz, Domestic Uptake of Green Energy Promoted by Opt-Out Tariffs, 5 NATURE Climate CHANGE 868 (2015), http://www.nature.com/ nclimate/journal/vaop/ncurrent/full/nclimate2681.html [https:/perma.cc/E7KP-XAB8] (finding large effects from automatic enrollment in green energy); Jolls, supra note 28 (suggesting that graphic warnings are helpful in informing people); Chetty et al., supra note 22 (finding large effects from automatic enrollment in savings plans). 
behavioral economics, and because they do not raise distinctive issues about individual rights. Here are the four pairs:

\section{Which of these policies do you prefer, as part of an antismoking campaign?}

1) Graphic warnings, with vivid pictures

of people who are sick from cancer.

2) Purely factual information, giving people statistical information about the risks from smoking.

Which of these policies do you prefer, as part of a campaign to encourage people to save for retirement?

1) Automatic enrollment of employees in savings plans, subject to "opt out" if employees do not want to participate.

2) Financial literacy programs at the workplace, so that employees are educated about retirement options.

Which of these policies do you prefer, as part of a program to reduce pollution?

1) Automatic enrollment of customers in slightly more expensive "green" (environmentally friendly) energy, subject to "opt out" if customers want another, slightly less expensive energy source.

Which of these policies do you prefer, as a way of encouraging water conservation?

1) The government requires hotels to select a default policy of "environmentfriendly rooms" in which towels left on the racks are not washed. If people want their towels washed, they can tell the front desk, and their towels will be washed daily.
2) Educational campaigns so that consumers can learn the advantages of green (environmentally friendly) energy.

\section{A. Respondents in the Neutral Condition (Condition 1)}

In a neutral condition, in which people were provided with no information about the effectiveness of System 1 or System 2 nudges, majorities consistently showed a clear preference for System 2 nudges. The aggregate data look like this: 
Table 1: Preferences as Between the System 1 and System 2 Nudge When Given No Information About Their Effectiveness

\begin{tabular}{|c|c|c|}
\hline \multirow{2}{*}{ Issue } & \multicolumn{2}{|c|}{ Percentage of Respondents (n=430) Who: } \\
\cline { 2 - 3 } & Prefer System 1 Nudge & Prefer System 2 Nudge \\
\hline Smoking & $45 \%$ & $55 \%$ \\
\hline Savings & $43 \%$ & $57 \%$ \\
\hline Energy & $26 \%$ & $74 \%$ \\
\hline Water & $32 \%$ & $68 \%$ \\
\hline
\end{tabular}

The preference for System 2 nudges is strongest in the cases of pollution reduction and water conservation. With respect to reducing pollution, the likely judgment is that it is better for people to learn and make their own choices than for them to be defaulted into an energy source that might turn out to be more expensive or less reliable. (I will turn to potential political divisions in Part II.E.) Participants might well have been concerned that people would not take the trouble to opt out and thus face higher electricity bills without their explicit consent. ${ }^{52}$ In the case of water conservation, money is not involved, but more people also favored System 2 nudges, perhaps because of a concern about defaulting guests into a situation that might not be in their interest (involving unwashed and perhaps dirty towels). ${ }^{53}$

Although majority preference for System 2 nudges is consistent, large numbers of people do favor System 1 nudges in all four contexts. One reason might be that many participants believe System 1 nudges to be more effective, so long as no information is provided on that question. The 45 percent of respondents who preferred graphic warnings for cigarettes might well have believed that, if the goal is to address a serious public-health problem, such warnings are more likely to work than purely factual information. Another reason might be that some System 1 nudges seem to impose lower decisionmaking burdens on choosers, as in the cases of default rules for saving, energy, and water conservation. If a System 1 nudge makes things a great deal easier for people, and does not require them to act, it might appear to

52. Note, however, that most Americans do support automatic enrollment in green energy. See SUNSTEIN, supra note 33, at 121-22.

53. Compare here the analogous finding that while most Americans reject the automatic registration of people as organ donors, they favor the forced choice of whether to be organ donors when they receive their driver's licenses. See id. 
be preferable. ${ }^{54}$ System 2 nudges, by contrast, seem to require a larger apparatus (consider financial education), and a greater investment of time and attention from choosers.

\section{B. Respondents Informed that the System 1 Nudge Is "Significantly More Effective" (Condition 2)}

In the neutral condition, people's preferences could have any number of sources. To obtain some understanding of what motivated those preferences, a different group of people was asked to assume that the System 1 nudge was "significantly more effective" with respect to each of the four goals. The hypothesis was that these three words would lead to a major increase in the percentage of people who preferred System 1 nudges.

The hypothesis was confirmed, but in a qualified way:

Table 2: Preferences as Between the System 1 and System 2 Nudge When the System 1 Nudge Is "Significantly More Effective"

\begin{tabular}{|c|c|c|}
\hline \multirow{2}{*}{ Issue } & \multicolumn{2}{|c|}{ Percentage of Respondents Who Prefer System 1 Nudge } \\
\cline { 2 - 3 } & & $\begin{array}{c}\text { Told that System 1 Nudge Is } \\
\text { "Significantly More Effective" } \\
(n=407)\end{array}$ \\
\hline Smoking & $45 \%$ & $57 \%$ \\
\hline Savings & $43 \%$ & $55 \%$ \\
\hline Energy & $26 \%$ & $38 \%$ \\
\hline Water & $32 \%$ & $42 \%$ \\
\hline
\end{tabular}

There are two noteworthy results here. First, the shift toward System 1 nudges is statistically significant for all four issues (using chisquare analysis, two-tailed $p<0.05$ for each question), but it is not massive. ${ }^{55}$ Second, the shift is essentially the same for all four questions. Indeed, it is remarkably consistent, with no significant differences across questions. When people are informed of the greater

54. See THALER, supra note 3, at 339-43 (discussing automatic enrollment and Save More Tomorrow plans); see generally CAss R. Sunstein, CHOOsing Not To CHoose (2015) (exploring why people might rationally choose not to choose).

55. Statistical significance was defined as $p<0.05$, using the Mann-Whitney $U$ test to test whether the changes between different survey conditions were significant. That is, it tested the null hypothesis that there was no change between survey conditions against an alternative hypothesis that there was an increase or decrease from one survey condition to another. 
effectiveness of System 1 nudges, support for System 1 nudges increases by ten to twelve percentage points.

We do not have enough data to speak of anything like an iron law here, but it is not too speculative to say that many people tend to think that System 2 nudges will be more effective or will serve as a better way to respect people's agency-but they will shift when they receive information about the comparative effectiveness of System 1 nudges. At the same time, many people (usually 40 percent or more) will have some degree of commitment, visceral or otherwise, to the superiority of the System 2 nudge. ${ }^{56}$ The addition of three words ("significantly more effective") is not enough to change that commitment.

\section{Respondents Informed that the System 1 Nudge Is "Significantly More Effective," with Quantitative Information (Condition 3)}

The words "significantly more effective" have a high degree of opacity. It is not clear what they mean. Once they are specified in quantitative terms, they might have a stronger or weaker impact. Suppose, for example, that people are told to assume that automatic enrollment would increase participation in savings plans from 40 percent to 90 percent, or that graphic warnings would save 200,000 lives annually - but that the System 2 alternatives would have essentially no impact. Under those assumptions, it would not be easy to reject the idea that System 1 nudges are better. To reject that idea, one would have to have concerns about the outcomes (saving lives is good, but the value of increased participation in savings plans is less obvious), or to put a very high premium indeed on a certain conception of personal agency. ${ }^{57}$ Alternatively, a System 1 nudge might be "significantly" more effective in a statistical sense, but its comparative advantage might be modest. If so, we might expect to see the same results as in the neutral condition - or even a movement in the direction of System 2 nudges.

To understand the effects of quantitative information, participants were asked to assume specified numerical disparities in favor of System

56. The survey did not directly measure the strength of people's commitments; it asked for preferences and did not measure their intensity.

57. On the complexities here, see generally Luc Bovens, The Ethics of Nudge, in PREFERENCE CHANGE 207 (Till Grüne-Yanoff \& Sven Ove Hansson eds., 2009) (exploring whether nudges are consistent with respect for autonomy); Moles, supra note 34 (defending much nudging as respectful of autonomy). 
1 nudges - not so stark as in the examples just given, but nonetheless lopsided.

- Antismoking Campaign: "Assume that [the System 1 nudge] is far more effective. It reduces smoking by 20 percent, while [the System 2 nudge] reduces smoking by 5 percent."

- Encouraging Retirement Savings: "Assume that [the System 1 nudge] is far more effective. It leads 90 percent of workers to enroll in savings plans, whereas [the System 2 nudge] leads only 55 percent to enroll in such plans."

- Reducing Pollution: "Assume that [the System 1 nudge] is far more effective. It cuts pollution by 40 percent, whereas [the System 2 nudge] cuts pollution by just 5 percent."

- Encouraging Water Conservation: "Assume that [the System 1 nudge] is far more effective. On average it cuts water use from washing towels by 70 percent, whereas [the System 2 nudge] cuts water use from washing towels by 10 percent."

Here are the results:

Table 3: Preferences as Between the System 1 and System 2 Nudge When the System 1 Nudge Is "Significantly More Effective," with Quantitative Information

\begin{tabular}{|c|c|c|c|}
\hline \multirow{2}{*}{} & \multicolumn{3}{|c|}{ Percentage of Respondents Who Prefer System 1 Nudge } \\
\cline { 2 - 4 } & Told that System 1 & $\begin{array}{c}\text { Told that System 1 } \\
\text { Nudge Is } \\
\text { "Significantly } \\
\text { More Effective" } \\
(n=407)\end{array}$ & $\begin{array}{c}\text { Effective, with } \\
\text { Quantification } \\
(n=435)\end{array}$ \\
\hline Issue & $\begin{array}{c}\text { Neutral Condition } \\
(n=430)\end{array}$ & $\begin{array}{c}\text { M7\% } \\
58 \%\end{array}$ \\
\hline Smoking & $45 \%$ & $55 \%$ & $56 \%$ \\
\hline Savings & $43 \%$ & $38 \%$ & $43 \%$ \\
\hline Energy & $26 \%$ & $42 \%$ & $47 \%$ \\
\hline Water & $32 \%$ & & \\
\hline
\end{tabular}

It should be clear that the quantitative information did not have a larger effect than the words "significantly more effective." Quite surprisingly, that information produced no statistically significant changes. One reason may be that the numerical differences were not particularly extreme; they plausibly reflected the kind of disparity that a purely qualitative account ("significantly more effective") would 
suggest. If so, the numbers provided no additional information. Another reason may be that the people who favored System 2 nudges, even in the face of a qualitative explanation that it would be less effective, did so because of a strong preference for what they saw as personal agency, and hence could not be moved even by fairly impressive numbers. It is natural to wonder whether a difference between the qualitative and the quantitative information would emerge in a between-subjects design, and I answer that question below. (To spoil the surprise: it does. ${ }^{58}$ )

\section{Respondents Informed that the System 2 Nudge Is "Significantly More Effective" (Condition 4)}

If it is assumed that System 2 nudges are "significantly more effective," we might expect that very large majorities would endorse them. If a nudge increases people's own capacities and also produces the desired result, it would seem far preferable to a less effective intervention that does not educate people in any way. The principal qualification is that, if a nudge is effective in producing a result that people do not like, then they will of course reject it for that very reason. (Most people would not like a nudge that is effective in encouraging people to use illegal drugs or to text while driving.) I will turn to this point below.

To test this hypothesis, I asked survey respondents whether they preferred System 1 or System 2 nudges on the assumption that the System 2 nudges were "significantly more effective." Here are the results:

Table 4: Preferences as Between the System 1 and System 2 Nudge When the System 2 Nudge Is "Significantly More Effective"

\begin{tabular}{|c|c|c|}
\hline \multirow{2}{*}{ Issue } & \multicolumn{2}{|c|}{ Percentage of Respondents Who Prefer System 1 Nudge } \\
\cline { 2 - 3 } & & $\begin{array}{c}\text { Told that System 2 Nudge Is } \\
\text { "Significantly More Effective" } \\
(n=435)\end{array}$ \\
\hline Smoking & $45 \%$ & $43 \%$ \\
\hline Savings & $43 \%$ & $44 \%$ \\
\hline Energy & $26 \%$ & $26 \%$ \\
\hline Water & $32 \%$ & $29 \%$ \\
\hline
\end{tabular}

58. See infra Table 15. 
Most surprisingly, the assumption of the comparatively greater effectiveness of System 2 nudges does not produce any shift in their direction. The numbers are essentially identical-a highly unexpected finding. Any explanation remains speculative, but it is possible that those who supported System 2 nudges already assumed that they would be more effective, so the three additional words added no new information. Alternatively, some people might think that System 1 nudges have some independent advantage (for example, because they operate automatically and cheaply), or that System 2 nudges have some independent disadvantage (for example, because they require a greater investment in time and attention). System 1 supporters might have stronger preferences than System 2 supporters and thus may be less likely to be persuaded by effectiveness arguments. ${ }^{59}$ For example, automatic enrollment in a savings plan might be more desirable than financial literacy programs, simply because it does not impose the costs and burdens of the latter. The same is true of automatic enrollment in green energy. It is also true that most people already prefer System 2 nudges and hence fewer people are available to be moved.

Some of these possibilities suggest that the lack of an effect from assuming that System 2 nudges are more effective is similar to the lack of effect of the quantitative information. ${ }^{60}$ Some people prefer System 1 nudges even if they believe them to be less effective. They might be engaging in some kind of informal cost-benefit analysis (a point to which I will return). It is also reasonable to ask whether we would observe the same results in a within-subjects design - that is, where participants see and answer all of the questions within a survey-a question answered in Part IV. (More surprise spoiling: we do not observe the same results. ${ }^{61}$ )

\section{E. Respondent Preferences by Partisan Affiliation}

Earlier work strongly suggests that in general, partisan divisions do not explain people's judgments about nudges. ${ }^{62}$ What matters is the

59. I am grateful to Ralph Hertwig for help with the ideas in this paragraph.

60. See supra Part II.C.

61. See infra Table 15.

62. See Cass R. Sunstein, Do People Like Nudges?, ADMIN. L. REV. (forthcoming 2016) (manuscript at 7), http://ssrn.com/abstract=2604084 [https://perma.cc/43AG-A8DP]; David Tannenbaum, Craig Fox \& Todd Rogers, On the Misplaced Politics of Behavioral Policy Interventions 10 (2014) (unpublished manuscript), http://home.uchicago.edu/davetannenbaum/ documents/partisan\%20nudge\%20bias.pdf [https://perma.cc/Y3AL-Z4SC] (finding that people 
valence of the particular nudge. ${ }^{63}$ In other words, Republicans do not like nudges more or less than Democrats do; within limits, they tend to like nudges that steer people in directions of which they approve, and the same is true of Democrats. ${ }^{64}$ Do political affiliations explain people's preferences for System 1 or System 2 nudges? Here are the results in full:

Table 5: Preferences as Between System 1 and System 2 Nudges by Partisan Affiliation (Condition 1)

\begin{tabular}{|c|c|c|c|c|c|c|}
\hline \multirow{2}{*}{ Issue } & \multicolumn{5}{|c|}{ Percentage of Respondents Who: } \\
\cline { 2 - 7 } & \multicolumn{3}{|c|}{ Prefer System 1 Nudge } & \multicolumn{2}{c|}{ Prefer System 2 Nudge } \\
\cline { 2 - 7 } & Dem. & Rep. & Indep. & Dem. & Rep. & Indep. \\
\hline Smoking & $50 \%$ & $44 \%$ & $40 \%$ & $50 \%$ & $56 \%$ & $60 \%$ \\
\hline Savings & $42 \%$ & $48 \%$ & $39 \%$ & $58 \%$ & $52 \%$ & $61 \%$ \\
\hline Energy & $34 \%$ & $24 \%$ & $19 \%$ & $66 \%$ & $76 \%$ & $81 \%$ \\
\hline Water & $42 \%$ & $27 \%$ & $26 \%$ & $58 \%$ & $73 \%$ & $74 \%$ \\
\hline
\end{tabular}

Note: Respondents were: 163 Democrats, 142 Republicans, and 125 independents.

Table 6: Preferences by Partisan Affiliation When the System 1 Nudge Is "Significantly More Effective" (Condition 2)

\begin{tabular}{|c|c|c|c|c|c|c|}
\hline \multirow{2}{*}{ Issue } & \multicolumn{5}{|c|}{ Percentage of Respondents Who: } \\
\cline { 2 - 7 } & \multicolumn{3}{|c|}{ Prefer System 1 Nudge } & \multicolumn{2}{c|}{ Prefer System 2 Nudge } \\
\cline { 2 - 7 } & Dem. & Rep. & Indep. & Dem. & Rep. & Indep. \\
\hline Smoking & $62 \%$ & $57 \%$ & $52 \%$ & $38 \%$ & $43 \%$ & $48 \%$ \\
\hline Savings & $60 \%$ & $55 \%$ & $49 \%$ & $40 \%$ & $45 \%$ & $51 \%$ \\
\hline Energy & $48 \%$ & $31 \%$ & $34 \%$ & $52 \%$ & $69 \%$ & $66 \%$ \\
\hline Water & $51 \%$ & $36 \%$ & $38 \%$ & $49 \%$ & $64 \%$ & $62 \%$ \\
\hline
\end{tabular}

Note: Respondents were: 163 Democrats, 142 Republicans, and 125 independents.

do not, across political lines, like or dislike nudges in general; their judgments are based on their own political attitudes).

63. SUNSTEIN, supra note 33, at 151, 158 (exploring partisan similarities and differences); Jung \& Mellers, supra note 33, at 72 (same); Sunstein, supra note 62, at 7 (same).

64. See Sunstein, supra note 62, at 19-20. 
Table 7: Preferences by Partisan Affiliation When the System 1 Nudge Is "Significantly More Effective," with Quantitative Information (Condition 3)

\begin{tabular}{|c|c|c|c|c|c|c|}
\hline \multirow{2}{*}{ Issue } & \multicolumn{5}{|c|}{ Percentage of Respondents Who: } \\
\cline { 2 - 7 } & \multicolumn{3}{|c|}{ Prefer System 1 Nudge } & \multicolumn{2}{c|}{ Prefer System 2 Nudge } \\
\cline { 2 - 7 } & Dem. & Rep. & Indep. & Dem. & Rep. & Indep. \\
\hline Smoking & $61 \%$ & $56 \%$ & $56 \%$ & $39 \%$ & $44 \%$ & $44 \%$ \\
\hline Savings & $58 \%$ & $51 \%$ & $57 \%$ & $42 \%$ & $49 \%$ & $43 \%$ \\
\hline Energy & $47 \%$ & $38 \%$ & $42 \%$ & $53 \%$ & $62 \%$ & $58 \%$ \\
\hline Water & $52 \%$ & $41 \%$ & $48 \%$ & $48 \%$ & $59 \%$ & $52 \%$ \\
\hline
\end{tabular}

Note: Respondents were: 165 Democrats, 138 Republicans, and 132 independents.

Table 8: Preferences by Partisan Affiliation When the System 2 Nudge Is "Significantly More Effective" (Condition 4)

\begin{tabular}{|c|c|c|c|c|c|c|}
\hline \multirow{2}{*}{ Issue } & \multicolumn{5}{|c|}{ Percentage of Respondents Who: } \\
\cline { 2 - 7 } & \multicolumn{3}{|c|}{ Prefer System 1 Nudge } & \multicolumn{2}{c|}{ Prefer System 2 Nudge } \\
\cline { 2 - 7 } & Dem. & Rep. & Indep. & Dem. & Rep. & Indep. \\
\hline Smoking & $53 \%$ & $35 \%$ & $39 \%$ & $47 \%$ & $65 \%$ & $61 \%$ \\
\hline Savings & $47 \%$ & $37 \%$ & $47 \%$ & $53 \%$ & $63 \%$ & $53 \%$ \\
\hline Energy & $28 \%$ & $24 \%$ & $25 \%$ & $72 \%$ & $76 \%$ & $75 \%$ \\
\hline Water & $41 \%$ & $20 \%$ & $23 \%$ & $59 \%$ & $80 \%$ & $77 \%$ \\
\hline
\end{tabular}

Note: Respondents were: 169 Democrats, 131 Republicans, and 133 independents.

There are many numbers here, but the basic story is straightforward. A majority of Republicans, Democrats, and independents all favor System 2 nudges, with just one qualification: Democrats are evenly split with respect to antismoking nudges. Both qualitative and quantitative information about the greater effectiveness of System 1 nudges produces an increase of about 10 to 20 percent in favor of System 1 nudges - and essentially the same degree of change is observed for all three groups. For all three groups, the assumption that System 2 nudges are significantly more effective produces results quite similar to those in the neutral condition. Notably, none of the differences between Condition 1 and Condition 4 , for any partisan affiliation, is statistically significant. ${ }^{65}$

65. In these cases, I could not reject the null hypothesis that the differences between Condition 1 and Condition 4 were irrelevant for Democrats, Republicans, and independents. The differences for Republican respondents for smoking and saving might look statistically significant, but they are not. 
The largest and most important finding here is that in many of the conditions, the differences among Democrats, Republicans, and independents are not significant. Their judgments as between System 1 and System 2 nudges are broadly in line with one another. But in some conditions, Democrats are more inclined to System 1 nudges than are Republicans and independents. In all conditions, for example, Democrats are more favorably disposed than Republicans or independents to a System 1 nudge for water conservation; the difference is statistically significant $(p<0.05)$. In Condition 2, Democrats are more favorably disposed than Republicans or Independents to a System 1 nudge for energy. In Condition 4, Democrats are more favorably disposed than Republicans to a System 1 nudge for smoking.

We can offer some plausible explanations for these differences. Democrats are comparatively more enthusiastic about green energy and water conservation, and very possibly antismoking efforts as well; to them, a System 1 nudge might seem more appealing if it is thought to be more effective. Republicans might be more likely to favor a System 2 nudge, especially for green energy or water conservation, to preserve personal agency. Notably, however, there were no significant differences among the three groups in terms of movements across conditions.

There is a quite fundamental point here. When people are enthusiastic about achieving the end result, they are probably more likely to support a System 1 nudge; when they are doubtful about the end, a System 2 nudge will seem preferable, above all because it is better in terms of retaining personal agency. We shall now find more evidence in this vein.

\section{Three Distinct Issues: Voting, CHILDREN, AND ABORTION}

The range of System 1 and System 2 nudges is of course exceptionally wide. For example, some nudges promote rights by making them easier to enjoy; consider, for example, simplified voter registration. Some nudges involve children. Teachers impose mandates on elementary school children, but they also nudge them in various ways: to do their homework, to act courteously, and to avoid disrupting classes. Some nudges discourage the use of rights. We could easily imagine efforts to steer people away from certain religious practices, or to discourage them from exercising their right to sexual privacy; proabstinence nudges are one example. 
A. Testing Preferences as Between the System 1 and System 2 Nudge in the Context of the Three Distinctive Issues

As illustrations of these distinctive kinds of nudges, I tested people's judgments about voting, childhood obesity, and abortion. For the neutral Condition 1, the three pairs looked like this:

Which of these policies do you prefer, as part of a program to increase voter registration?

1) Automatic voter registration, so that
when people receive their driver's licenses,
and show they are domiciled in your state,
they are automatically registered as voters.

2) A public education campaign to convince people to register to vote.

Which of these policies do you prefer, as part of a program to combat childhood obesity?

1) Redesigning school cafeterias so that healthy, low-calorie options are in the most visible locations.

2) Educating parents about the problem of childhood obesity and how to combat it.

Which of these policies do you prefer, as a means of discouraging abortions? (Please indicate which you prefer even if you do not like either.)

1) Requiring pregnant women, before having an abortion, to see vivid photos of fetuses, designed to show that they are merely very young children.
2) Requiring pregnant women, before having an abortion, to speak briefly with a doctor about whether they really believe, on reflection, that an abortion is the right choice, in light of the moral issues involved.

Just as with the four standard questions from Part II, people participating in Condition 2 were asked about their preference under the assumption that the System 1 nudge was "significantly more effective." In Condition 4, participants were asked about their preference under the assumption that the System 2 nudge was "significantly more effective." In terms of Condition 3, where the assumption that the System 1 nudge was "significantly more effective" was also supported by quantitative information, the survey questions looked like this:

- Increasing Voter Registration: "Which of these policies do you prefer, as part of a program to increase voter registration? Assume that 1) is significantly more effective in increasing voter registration. It registers 40 percent of currently unregistered voters and 2) registers 10 percent of currently unregistered voters." 
- Combatting Childhood Obesity: "Which of these policies do you prefer, as part of a program to combat childhood obesity? Assume that 1) is far more effective. On average, it cuts caloric consumption by 30 percent, whereas 2) cuts caloric consumption by just 5 percent."

- Discouraging Abortions: "Which of these policies do you prefer, as a means of discouraging abortions? Assume that 1) is significantly more effective. It cuts the abortion rate by 30 percent, whereas 2 ) cuts the abortion rate by 5 percent. (Please indicate which you prefer even if you do not like either.)"

\section{B. General Results for the Preference as Between the System 1 and System 2 Nudge in the Context of Three Distinctive Issues}

The right to vote has a special resonance, and any effort to nudge people to exercise that right is likely to attract significant support. The right to choose abortion has a similar resonance, even if it is far more controversial; an effort to nudge people to choose abortion, or not to choose it, will raise questions that are unique to that context. The question of childhood obesity is distinctive for a different reason: it involves children, where System 1 nudges might be more acceptable. (Parents appeal to System 1 all the time. ${ }^{66}$ ) We might expect that majorities would be especially sympathetic to System 1 nudges to encourage voting; especially unsympathetic to System 1 nudges to discourage abortion; and especially sympathetic to System 1 nudges to reduce childhood obesity. With some qualifications, that is what we find.

66. I am confident that this proposition is true, but I might be somewhat unusual in actually explaining System 1 and System 2 to my son, five years old at the time. He has a keen interest in toys, and in my buying him more of them, even though he already has plenty. One day I explained to him that though his System 1 wants more toys, his System 2 knows that he does not need them. He understood the distinction immediately (though for a month or so he referred to his "Part 1 " and "Part 2"). After struggling with his emotions whenever we passed toy stores, he finally asked, "Daddy, do I even have a System 2?" 
1. Increasing Voter Registration. Most Americans prefer automatic voter registration to efforts to encourage people to register. The changes in assumptions do not produce statistically significant changes in levels of support:

Table 9: Preference as Between the System 1 and System 2 Nudge When the Nudge Aims to Increase Voter Registration

\begin{tabular}{|l|c|c|}
\hline \multirow{2}{*}{ Condition } & \multicolumn{2}{|c|}{ Percentage of Respondents Who: } \\
\cline { 2 - 3 } & Prefer System 1 Nudge & Prefer System 2 Nudge \\
\hline 1) Neutral & $57 \%$ & $43 \%$ \\
\hline $\begin{array}{l}\text { 2) System 1 Nudge "Significantly } \\
\text { More Effective" }\end{array}$ & $62 \%$ & $38 \%$ \\
\hline $\begin{array}{l}\text { 3) System 1 Nudge "Significantly } \\
\text { More Effective," with Quantitative } \\
\text { Information }\end{array}$ & $61 \%$ & $39 \%$ \\
\hline $\begin{array}{l}\text { 4) System 2 Nudge "Significantly } \\
\text { More Effective" }\end{array}$ & $52 \%$ & $48 \%$ \\
\hline
\end{tabular}

There are two noteworthy findings here. The first is that a majority prefers the System 1 nudge in all four conditions. The reason is probably a strong (moral) judgment or intuition that people should be voters by default; they should not have to take steps to attain that status. The second is that with respect to automatic voter registration, movements do not occur across the three conditions, as they sometimes do for the four nudges previously discussed. ${ }^{67}$

2. Combatting Childhood Obesity. For childhood obesity, a small majority favors cafeteria design over parental education, except when people are asked to assume that the latter is significantly more effective:

67. In particular, we observe movements from Condition 1 to Conditions 2 and 3 for the four standard nudges discussed in Part II; no such movements are found here. 
Table 10: Preference as Between the System 1 and System 2 Nudge to Combat Childhood Obesity

\begin{tabular}{|l|c|c|}
\hline \multirow{2}{*}{ Condition } & \multicolumn{2}{|c|}{ Percentage of Respondents Who: } \\
\cline { 2 - 3 } & Prefer System 1 Nudge & Prefer System 2 Nudge \\
\hline 1) Neutral & $53 \%$ & $47 \%$ \\
\hline $\begin{array}{l}\text { 2) System 1 Nudge "Significantly } \\
\text { More Effective" }\end{array}$ & $53 \%$ & $47 \%$ \\
\hline $\begin{array}{l}\text { 3) System 1 Nudge "Significantly } \\
\text { More Effective," with Quantitative } \\
\text { Information }\end{array}$ & $63 \%$ & $37 \%$ \\
\hline $\begin{array}{l}\text { 4) System 2 Nudge "Significantly } \\
\text { More Effective" }\end{array}$ & $48 \%$ & $52 \%$ \\
\hline
\end{tabular}

In the three "informed" conditions, only one shift is significant: with quantitative information, there is an increase in support for cafeteria design. In general, we do not find the same kinds of shifts as are observed for the four more standard nudges.

3. Discouraging Abortions. For abortion, the System 2 nudge is preferred by a substantial majority. (Note that for this question, participants were specifically asked to choose one option even if they did not like either, acknowledging that on that highly sensitive issue, some respondents might reject both nudges.) The preference for the System 2 nudge does not shift significantly across the four conditions:

Table 11: Preference as Between the System 1 and System 2 Nudge When the Nudge Aims to Discourage Abortions

\begin{tabular}{|l|c|c|}
\hline \multirow{2}{*}{ Condition } & \multicolumn{2}{|c|}{ Percentage of Respondents Who: } \\
\cline { 2 - 3 } & Prefer System 1 Nudge & Prefer System 2 Nudge \\
\hline 1) Neutral & $25 \%$ & $75 \%$ \\
\hline $\begin{array}{l}\text { 2) System 1 Nudge "Significantly } \\
\text { More Effective" }\end{array}$ & $34 \%$ & $66 \%$ \\
\hline $\begin{array}{l}\text { 3) System 1 Nudge "Significantly } \\
\text { More Effective," with Quantitative } \\
\text { Information }\end{array}$ & $33 \%$ & $67 \%$ \\
\hline $\begin{array}{l}\text { 4) System 2 Nudge "Significantly } \\
\text { More Effective" }\end{array}$ & $29 \%$ & $71 \%$ \\
\hline
\end{tabular}


The best explanation here is probably that, for an intensely personal decision of this kind, most people do not want the government to attempt to move people by engaging or exploiting System 1. If so, movements across the conditions should not be expected. For many people, of course, abortion is a morally questionable or unacceptable choice, and for them, a System 1 nudge might seem better, either because it is more likely to be effective or because it is a more pointed and direct response to those who are considering that choice. Hence the steady minority support for the System 1 nudge is also unsurprising.

\section{Respondent Preferences by Partisan Affiliation}

What is the role of political divisions? We might well expect that it would be larger than in the four standard cases, and in some respects it is, but the full story is not entirely straightforward. Here are the results:

Table 12: Preferences by Partisan Affiliation When the Nudge Aims to Increase Voter Registration

\begin{tabular}{|l|c|c|c|c|c|c|}
\hline \multirow{2}{*}{\multicolumn{1}{|c|}{ Condition }} & \multicolumn{5}{|c|}{ Percentage of Respondents Who: } \\
\cline { 2 - 8 } & \multicolumn{2}{|c|}{ Prefer System 1 Nudge } & \multicolumn{2}{c|}{ Prefer System 2 Nudge } \\
\cline { 2 - 8 } & Dem. & Rep. & Indep. & Dem. & Rep. & Indep. \\
\hline 1) Neutral & $65 \%$ & $53 \%$ & $52 \%$ & $35 \%$ & $47 \%$ & $43 \%$ \\
\hline $\begin{array}{l}\text { 2) System 1 Nudge } \\
\text { "Significantly More Effective" }\end{array}$ & $63 \%$ & $53 \%$ & $57 \%$ & $37 \%$ & $47 \%$ & $43 \%$ \\
\hline $\begin{array}{l}\text { 3) System 1 Nudge } \\
\text { "Significantly More Effective," } \\
\text { with Quantitative Information }\end{array}$ & $71 \%$ & $54 \%$ & $58 \%$ & $29 \%$ & $46 \%$ & $42 \%$ \\
\hline $\begin{array}{l}\text { 4) System 2 Nudge } \\
\text { "Significantly More Effective" }\end{array}$ & $55 \%$ & $53 \%$ & $48 \%$ & $45 \%$ & $47 \%$ & $52 \%$ \\
\hline
\end{tabular}


Table 13: Preferences by Partisan Affiliation When the Nudge Aims to Combat Childhood Obesity

\begin{tabular}{|l|c|c|c|c|c|c|}
\hline \multirow{2}{*}{\multicolumn{1}{|c|}{ Condition }} & \multicolumn{6}{|c|}{ Percentage of Respondents Who: } \\
\cline { 2 - 7 } & \multicolumn{2}{|c|}{ Prefer System 1 Nudge } & \multicolumn{2}{c|}{ Prefer System 2 Nudge } \\
\cline { 2 - 7 } & Dem. & Rep. & Indep. & Dem. & Rep. & Indep. \\
\hline 1) Neutral & $61 \%$ & $45 \%$ & $51 \%$ & $39 \%$ & $54 \%$ & $49 \%$ \\
\hline $\begin{array}{l}\text { 2) System 1 Nudge } \\
\text { "Significantly More Effective" }\end{array}$ & $59 \%$ & $48 \%$ & $52 \%$ & $41 \%$ & $52 \%$ & $48 \%$ \\
\hline $\begin{array}{l}\text { 3) System 1 Nudge } \\
\text { "Significantly More Effective," } \\
\text { with Quantitative Information }\end{array}$ & $70 \%$ & $52 \%$ & $67 \%$ & $30 \%$ & $48 \%$ & $33 \%$ \\
\hline $\begin{array}{l}\text { 4) System 2 Nudge } \\
\text { "Significantly More Effective" }\end{array}$ & $51 \%$ & $43 \%$ & $49 \%$ & $49 \%$ & $57 \%$ & $51 \%$ \\
\hline
\end{tabular}

Table 14: Preferences by Partisan Affiliation When the Nudge Aims to Discourage Abortions

\begin{tabular}{|l|c|c|c|c|c|c|}
\hline \multirow{2}{*}{\multicolumn{1}{|c|}{ Condition }} & \multicolumn{5}{|c|}{ Percentage of Respondents Who: } \\
\cline { 2 - 8 } & \multicolumn{3}{|c|}{ Prefer System 1 Nudge } & \multicolumn{2}{|c|}{ Prefer System 2 Nudge } \\
\cline { 2 - 8 } & Dem. & Rep. & Indep. & Dem. & Rep. & Indep. \\
\hline 1) Neutral & $20 \%$ & $32 \%$ & $23 \%$ & $80 \%$ & $68 \%$ & $77 \%$ \\
\hline $\begin{array}{l}\text { 2) System 1 Nudge } \\
\text { "Significantly More Effective" }\end{array}$ & $30 \%$ & $42 \%$ & $29 \%$ & $70 \%$ & $58 \%$ & $71 \%$ \\
\hline $\begin{array}{l}\text { 3) System 1 Nudge } \\
\text { "Significantly More Effective," } \\
\text { with Quantitative Information }\end{array}$ & $25 \%$ & $43 \%$ & $31 \%$ & $75 \%$ & $57 \%$ & $69 \%$ \\
\hline $\begin{array}{l}\text { 4) System 2 Nudge } \\
\text { "Significantly More Effective" }\end{array}$ & $24 \%$ & $34 \%$ & $30 \%$ & $76 \%$ & $66 \%$ & $70 \%$ \\
\hline
\end{tabular}

The most consistent difference can be found in the area of discouraging abortions, where higher percentages of Republicans are more inclined to favor the System 1 nudge across all four conditions. In three of the four conditions, the difference for that question is statistically significant between Democrats and Republicans (the exception is when respondents are told the System 2 nudge is significantly more effective).$^{68}$ For both increasing voter registration and combatting childhood obesity, the difference between Democrats

68. Using chi-square analysis, two-tailed $p<0.05$ for each question. 
and Republicans for the neutral condition is significant, and when they have been informed that there is a quantitative advantage to a System 1 nudge, Democrats and independents show a significant difference for voting. Republicans and independents show such a difference in relation to abortion when told that System 1 nudges are significantly more effective, both with and without actual numbers. Republicans and independents show such a difference in relation to childhood obesity when told that System 1 nudges are more effective with numbers. Interestingly, there is no significant difference of any kind when respondents are told that System 2 nudges are more effective.

Here as well, the details should not obscure the basic story: when issues are politically contested, there is more likely to be a partisan difference in terms of choice between System 1 and System 2 nudges. Apparently it is the case that if people strongly support a particular end, they will be more likely to support a System 1 nudge to attain it. ${ }^{69}$ I speculate that when the end seems especially important, the overriding consideration is how best to achieve that end, and people will favor the nudge that seems most likely to do that. Another consideration, perhaps explaining some of the results here, is that when people have an intense emotional reaction to some outcome (such as the use of illegal drugs), they might well favor a System 1 response (such as a graphic warning).

For the four standard cases in Part II, on the other hand, political affiliation usually did not explain people's choices between System 1 and System 2 nudges (with interesting exceptions, especially in the case of reducing pollution). By contrast, political affiliation mattered much more for abortion, voting, and childhood obesity. It would not, of course, be surprising to find that Democrats are less supportive of prolife nudges than Republicans, or that Republicans are less enthusiastic than Democrats about automatic voter registration or efforts to combat childhood obesity. ${ }^{70}$

\section{DigGing DeEPER INTO THE FINDINGS: FoLLOW-Up STUDIES}

The nationally representative survey offers a great deal of information about what people think, but it also leaves many mysteries. Why, for example, did the neutral condition produce essentially the

69. If so, are people motivated by System 1 or by System 2? I believe that System 1 is the right answer, but the current survey cannot prove the point.

70. See Sunstein, supra note 62, (manuscript at 10 tbl.2, 12 tbl.4, 19) (finding evidence to this effect). 
same results as the "System 2 nudge is significantly more effective" condition? Why did the "System 1 nudge is significantly more effective" condition produce the same results as the condition in which that advantage was displayed with impressive numbers? And why, exactly, do some people favor System 1 nudges, and others favor System 2 nudges?

To answer these questions, I conducted four follow-up studies, all on Amazon Mechanical Turk. The populations are not nationally representative, and for that reason, the results must be taken with a grain of salt. ${ }^{71}$ At the same time, the numbers in the neutral condition are closely in line with the nationally representative survey. It is not unreasonable to think that, in terms of the particular questions I am exploring here, the results would hold up with a nationally representative sample.

\section{A. Testing Preferences with a Within-Subjects Design}

The surveys discussed in Parts II and III involved a "betweensubjects" design. Different groups of participants saw different conditions, rather than all of them at once. That design has significant advantages, because it prevents contamination by previous answers. If questions are seen in isolation, responses cannot be affected by order effects, or by a particular factor that becomes highlighted only by virtue of its clear difference from a previous question. In a sense, the answers in a between-subjects design are pure, because a factor (say, comparative effectiveness) will not assume more salience than it would if people were looking at the conditions at the same time.

Nonetheless, there are also advantages to a "within-subjects" design, by which participants see, and answer, all of the questions in the same survey. For present purposes, the principal advantage is that with a within-subjects design, it is possible to test whether people's original answers shift after they are given information about comparative effectiveness. That question is important to test, because it reveals whether some people are strongly committed to System 1 or

71. For some relevant characteristics of participants in Amazon Mechanical Turk studies, see supra note 41 . The advantage of nationally representative surveys is, of course, that they involve a roughly accurate snapshot of the relevant public (in this case, the United States). By contrast, participants in online surveys on Amazon Mechanical Turk are self-selected; they choose to participate, and their judgments, interests, and values might be quite different from a nationally representative group. In the surveys presented here, however, there are only modest differences between participants in the Amazon Mechanical Turk survey and participants in the nationally representative survey when the same questions were asked. 
System 2 nudges - so committed that they will stick with one or the other even when effectiveness information stares them in the face. With a within-subjects design, we can also cast light on two questions raised by the between-subjects survey: (1) Does quantitative information really make no difference to people? (2) Are people really indifferent to whether System 2 nudges are significantly more effective?

I used Amazon Mechanical Turk to ask about four hundred people twenty-four questions, involving all of the areas tested above (with the exception of abortion ${ }^{72}$ ). Here are the results:

Table 15: Within-Subjects Results for the Preference as Between the System 1 and System 2 Nudge for Six of the Seven Issues Across the Four Conditions

\begin{tabular}{|c|c|c|c|c|}
\hline \multirow{2}{*}{ Issue } & \multicolumn{4}{|c|}{ Percentage of Respondents Who Prefer the System 1 Nudge } \\
\cline { 2 - 5 } & 1 & 2 & 3 & 4 \\
\hline Smoking & $41 \%$ & $57 \%$ & $67 \%$ & $30 \%$ \\
\hline Savings & $45 \%$ & $58 \%$ & $72 \%$ & $28 \%$ \\
\hline Energy & $36 \%$ & $50 \%$ & $69 \%$ & $19 \%$ \\
\hline Water & $42 \%$ & $55 \%$ & $67 \%$ & $21 \%$ \\
\hline Obesity & $61 \%$ & $71 \%$ & $78 \%$ & $29 \%$ \\
\hline Voting & $60 \%$ & $66 \%$ & $76 \%$ & $34 \%$ \\
\hline
\end{tabular}

Several things are relatively clear. The most important is that the pattern of responses is quite orderly. We see the general movements that we should expect. Comparative effectiveness information in favor of System 1 nudges increases support for System 1 nudges, quantitative information increases support still further, and comparative effectiveness information in favor of System 2 nudges increases support for System 2 nudges. In the two latter respects, we observe movements

72. This area was excluded on the ground that it is highly controversial, and it is not clear how much more would be learned in a within-subjects design. From the nationally representative survey, we know that most people will oppose System 1 nudges to discourage abortion even in a between-subjects design, and that the numbers do not move much across conditions. Because people's judgments about such nudges are likely to depend on their views about abortion (and hence effectiveness information showing that System 1 nudges do in fact discourage abortion does not move them), we do not expect major shifts in a within-subjects design. Admittedly, that hypothesis remains to be tested. 
that make sense, and that are not found in the between-subjects design. ${ }^{73}$

To offer a bit more detail: in general, the answers in the neutral condition are fairly close to what was found in the nationally representative sample. At the same time, and as anticipated, some of the movements across conditions are greater. From the neutral condition to the "System 1 nudge is significantly more effective" condition, the movements are in line with those in the nationally representative sample. But in the between-subjects design, the quantitative information makes a real difference. And for all questions, movements of at least 11 percent, and sometimes of more than 20 percent, can be found from the neutral condition to the "System 2 nudge is significantly more effective" condition. In this survey, then, the differences among the conditions produced reliable shifts in people's views.

There are two important qualifications. First, at least one-third of the population continued to favor the System 2 nudge in the withinsubjects condition, even when they were given numbers to support the comparatively greater effectiveness of the System 1 nudge. That result might be taken as surprising. Second, large percentages of people (usually around one-quarter) continued to favor the System 1 nudge in the within-subjects condition, even when they were informed that the System 2 nudge was significantly more effective. That result also seems surprising.

Although it does not involve a nationally representative sample, the within-subjects study provides useful information. It suggests that with information about greater comparative effectiveness, the number of people who shift to System 1 nudges will probably be greater in a within-subjects design - and that the appeal of the System 2 nudge will also be heightened, in that design, with evidence of greater effectiveness. At the same time, the within-subjects design fortifies the general conclusion that a certain percentage of the population will favor System 2 nudges even if they are significantly less effective, in large part because of a commitment to a certain conception of individual agency.

73. One reason involves "evaluability": in a within-subjects design with multiple questions, people can evaluate factors that might be hard to assess in the abstract. See Christopher Hsee, The Evaluability Hypothesis: An Explanation for Preference Reversals Between Joint and Separate Evaluations of Alternatives, 67 OrganizATIONAL BEHAV. \& HUM. DECISION Processes 247, 255 (1996) (urging that when people are making decisions that involve joint presentations, they can evaluate factors that might defy evaluation when options are presented separately). 


\section{B. Testing Beliefs About Effectiveness, as Opposed to Preference}

Both the between-subjects and the within-subjects designs ask people to register their preferences. They do not test people's independent judgments about effectiveness. Asking people about effectiveness should be illuminating: if people prefer System 2 nudges even though they think that System 1 nudges would be more effective, then we have good reason to think that a commitment to individual agency, or something like that, is driving their judgments.

Using Amazon Mechanical Turk, I asked about four hundred people the effectiveness question. The survey looked like this:

\begin{tabular}{|l|l|}
\hline $\begin{array}{l}\text { Which of these policies do you think would be more effective as part of an antismoking } \\
\text { campaign? }\end{array}$ \\
\hline $\begin{array}{l}\text { 1) Graphic warnings, with vivid pictures of } \\
\text { people who are sick from cancer. }\end{array}$ & $\begin{array}{l}\text { 2) Purely factual information, giving } \\
\text { people statistical information about the } \\
\text { risks from smoking }\end{array}$ \\
\hline
\end{tabular}

Which of these policies do you think would be more effective as part of a campaign to encourage people to save for retirement?

\begin{tabular}{|l|l|}
\hline $\begin{array}{l}\text { 1) Automatic enrollment of employees in } \\
\text { savings plans, subject to "opt out" if } \\
\text { employees do not want to participate. }\end{array}$ & $\begin{array}{l}\text { 2) Financial literacy programs at the } \\
\text { workplace, so that employees are } \\
\text { educated about retirement options. }\end{array}$ \\
\hline
\end{tabular}

Which of these policies do you think would be more effective as part of a program to reduce pollution?

1) Automatic enrollment of customers in slightly more expensive "green"

2) Educational campaigns so that

(environmentally friendly) energy, subject to "opt out" if customers want another,

slightly less expensive energy source.

Which of these policies do you think would be more effective at promoting water conservation?

1) The government requires hotels to select a default policy of "environmentfriendly rooms" in which towels left on the racks are not washed. If people want their towels washed, they can tell the front desk, and their towels will be washed daily.
2) The government requires hotels to provide guests with information about an "environment-friendly" policy in which towels left on the racks are not washed. People are encouraged to choose to take part, but if they do not choose to do so, their towels will be washed every day. 
Which of these policies do you think would be more effective in combatting childhood obesity?

1) Redesigning school cafeterias so that healthy, low-calorie options are in the most visible locations.

Which of these policies do you think would be more effective in increasing voter registration?

1) Automatic voter registration, so that when people receive their driver's licenses, and show they are domiciled in your state, they are automatically registered as voters.

Which of these policies do you think would be more effective as a means of discouraging abortions? (Please indicate which you prefer even if you do not like either.)

1) Requiring pregnant women, before having an abortion, to see vivid photos of fetuses, designed to show that they are merely very young children.
2) A public education campaign to convince people to register to vote.

Here are the results:

Table 16: Beliefs About Whether a System 1 or System 2 Nudge Is More Effective in the Context of Each of the Six Issues

\begin{tabular}{|c|c|c|}
\hline \multirow{2}{*}{ Issue } & \multicolumn{2}{|c|}{ Percentage of Respondents Who Believe: } \\
\cline { 2 - 3 } & System 1 Nudge Is More Effective & System 2 Nudge Is More Effective \\
\hline Smoking & $71 \%$ & $29 \%$ \\
\hline Savings & $53 \%$ & $47 \%$ \\
\hline Energy & $45 \%$ & $55 \%$ \\
\hline Water & $53 \%$ & $47 \%$ \\
\hline Obesity & $57 \%$ & $43 \%$ \\
\hline Voting & $75 \%$ & $25 \%$ \\
\hline Abortion & $30 \%$ & $70 \%$ \\
\hline
\end{tabular}

The most important finding is that majorities believe that the System 1 nudge is the more effective nudge for five of the seven questions-even though majorities prefer the System 1 nudge for only two (see Tables 1, 9, 10, and 11). We can plausibly infer that majorities will often prefer System 2 nudges even when they believe that System 1 nudges are more effective-strongly suggesting that personal agency 
drives some people in the direction of System 2 nudges. People's beliefs about effectiveness also appear to be influenced by their values. The abortion problem is the clearest on that count; the overwhelming majority (70 percent) say that the System 2 nudge would be more effective even though that conclusion is far from self-evident. We might question whether in giving this response, they are really saying what they think is more "effective" in discouraging abortion. It is far more likely that they are registering what they prefer, given their values.

To be sure, the population that answered the effectiveness question was not nationally representative, and we do not know whether an effectiveness-preference split would be observed in a nationally representative survey, with either a within-subjects or a between-subjects design. Nonetheless, we have seen that in the neutral condition and the "significantly more effective condition," the results on the Amazon Mechanical Turk survey reported here are very much in line with the results in the nationally representative sample. The effectiveness answers strongly suggest that a certain percentage of people will favor System 2 nudges even though they believe them to be less effective.

\section{Comparing the Assumptions that the System 1 Nudge Is "Significantly More Effective" or "Dramatically More Effective"}

In the main survey, the difference between Condition 1 on the one hand and Conditions 2 and 3 on the other was large, but not massive. For this reason, it is worth asking whether more people would prefer the System 1 nudge if the numbers showing its greater effectiveness were more dramatic. To test that question, I used the four standard questions in a within-subjects design, but offered exceptionally vivid accounts of the differential effectiveness:

- Antismoking Campaign: "Assume that 1) would be significantly more effective than 2), in the sense that it would prevent 15,000 premature deaths each year, whereas 2) would prevent only 500 . Which of the two would you prefer, with that assumption?"

- Encouraging Retirement Savings: "Assume that 1) would be significantly more effective than 2), in the sense that it would mean that 90 percent of employees would be enrolled in savings plans, whereas 2) would mean that only 30 percent would be enrolled. Which of the two would you prefer, with that assumption?" 
- Reducing Pollution: "Assume that 1) would be significantly more effective than 2), in the sense that it would cut air pollution by 50 percent (and prevent at least 2,000 annual deaths), whereas 2) would cut air pollution by just 5 percent (and prevent at least 200 annual deaths). Which of the two would you prefer, with that assumption?"

- Encouraging Water Conservation: “Assume that 1) would be significantly more effective than 2), in the sense that it would cut water usage at hotels by 10 percent, whereas 2) would cut such usage by just 1 percent. Which of the two would you prefer, with that assumption?"

With these formulations, the increase in preference for the System 1 nudge from Condition 1 to Condition 3 was indeed large:

Table 17: Preference as Between the System 1 and System 2 Nudge When the System 1 Nudge Is Dramatically More Effective

\begin{tabular}{|c|c|c|}
\hline \multirow{2}{*}{ Issue } & \multicolumn{2}{|c|}{ Percentage of Respondents Who Prefer the System 1 Nudge } \\
\cline { 2 - 3 } & Neutral Condition & $\begin{array}{c}\text { Given Quantitative Information } \\
\text { Showing that System 1 Nudge Is } \\
\text { Dramatically More Effective }\end{array}$ \\
\hline Smoking & $42 \%$ & $76 \%$ \\
\hline Savings & $42 \%$ & $67 \%$ \\
\hline Energy & $35 \%$ & $70 \%$ \\
\hline Water & $42 \%$ & $64 \%$ \\
\hline
\end{tabular}

There are two lessons, and both of them are surprising. The first is that the dramatic numbers in this survey produced movements (from a low of 22 percent to a high of 34 percent) that were not higher than those produced by less dramatic numbers (see Table 15). Apparently many people make a judgment about something relatively crude ("whether a big difference matters") and they decide to move, or not to move, accordingly. We might speculate that the difference between significantly greater effectiveness and dramatically greater effectiveness would be larger in a within-subjects design.

The second lesson is that, even with relatively stunning differences in effectiveness, a substantial number of people continued to prefer the System 2 nudge. This was the case for 24 percent of respondents who rejected the graphic cigarette warnings at the expense of 14,500 lives, 
and for the 30 percent of respondents who rejected the automatic enrollment in green energy programs at the expense of 1,800 lives.

What if the System 2 nudge were shown to be significantly more effective, not in the abstract, but with the benefit of numbers? To answer that question, I did a version of the immediately preceding survey with the identical numbers, except for one difference: System 2 was said to be the more effective one. The results, with four hundred participants, looked like this:

Table 18: Preference as Between the System 1 and System 2 Nudge When the System 2 Nudge Is Dramatically More Effective

\begin{tabular}{|c|c|c|}
\hline \multirow{2}{*}{ Issue } & \multicolumn{2}{|c|}{ Percentage of Respondents Who Prefer the System 1 Nudge } \\
\cline { 2 - 3 } & Neutral Condition & $\begin{array}{c}\text { Told System 2 Nudge Is } \\
\text { Dramatically More Effective }\end{array}$ \\
\hline Smoking & $41 \%$ & $19 \%$ \\
\hline Savings & $44 \%$ & $19 \%$ \\
\hline Energy & $34 \%$ & $14 \%$ \\
\hline Water & $45 \%$ & $17 \%$ \\
\hline
\end{tabular}

As should be expected, the assumption of quantitative data showing dramatically greater effectiveness of System 2 nudges had a substantial effect in this within-subjects survey. The shifts ranged from 20 percent to 28 percent. This was a large shift, and the increase in those preferring System 2 across the four categories was nearly lock-step. At the same time, a significant fraction of people (somewhat less than onefifth) continued to favor the System 1 nudge. It remains unclear why they did so. Perhaps they refused to accept the effectiveness numbers. Perhaps they believed that System 1 nudges have independent advantages.

\section{Testing Preferences with an "Either or Both" Option}

The topic here has been a required choice among two options: System 1 nudge or System 2 nudge? In many cases, however, it is possible to choose neither, or both. Earlier work has tested the "neither" question, and found that strong majorities of Americans and Europeans reject that approach; they like the relevant nudges. ${ }^{74}$ Earlier work has also found that if asked to approve or disapprove

74. See Sunstein, supra note 62, at 7; Lucia A. Reisch \& Cass R. Sunstein, Do Europeans Like Nudges?, 11 JUDGMENT \& DECISION MAKING 310, 311 (2016). 
System 1 nudges of the kind that have been tested here, strong majorities approve. But what if people were asked to choose System 1, System 2, or both?

Again using Amazon Mechanical Turk, I asked about four hundred people that question. Here are the results:

Table 19: Either or Both?

\begin{tabular}{|c|c|c|c|}
\hline \multirow{2}{*}{ Issue } & \multicolumn{3}{|c|}{ Percentage of Respondents Who Preferred: } \\
\cline { 2 - 4 } & System 1 Nudge & System 2 Nudge & Both \\
\hline Smoking & $10 \%$ & $44 \%$ & $46 \%$ \\
\hline Savings & $16 \%$ & $40 \%$ & $44 \%$ \\
\hline Energy & $10 \%$ & $56 \%$ & $34 \%$ \\
\hline
\end{tabular}

The most obvious lesson is that numerous people will support both, even though they will favor one or the other when they are forced to choose between them. For both smoking and savings, "both" did not fall that far short of obtaining majority support, and for air pollution, it attracted over one-third of respondents. At the same time, many people favored a System 2 nudge over "both," probably on the theory that the System 1 nudge is insufficiently respectful of individual agency, or that it adds nothing to the System 2 nudge. This is a noteworthy result; other works suggest that if people are asked whether they support a System 1 or System 2 nudge in isolation (smoking, savings, air pollution), they might well say yes. ${ }^{75}$

Further study would be quite valuable in order to illuminate these results. We might speculate that the likelihood that people will prefer "both" depends in part on their perception of the magnitude of the problem. If it is very serious, people might think: the more tools, the better. The question is whether the interest in individual agency, as it is perceived by those who favor System 2 nudges, outweighs that thought.

\section{POPUlar OPINION, LAw, AND PUBlic POLICY}

Survey evidence can tell us a great deal about what kinds of policies will produce public approval or disapproval. We know that both Americans and Europeans are broadly supportive of the kinds of nudges that have been implemented or under serious discussion in

75. See Reisch \& Sunstein, supra note 74, at 319; Sunstein, supra note 62 (manuscript at 9). 
recent years, and that this support generally cuts across partisan lines. ${ }^{76}$ We know too that when people are not asked to choose between System 1 nudges and System 2 nudges, and are simply asked whether they approve of a nudge, they tend to say yes. This includes, for example, graphic warnings designed to reduce smoking and distracted driving, and automatic enrollment in savings plans and green energy. ${ }^{77}$ We also know that Americans reject nudges that reflect what they see as illicit ends (such as religious favoritism) or those that are inconsistent with the values and interests of most choosers (such as automatic contributions to particular charities). ${ }^{78}$ There is a concern about manipulation, at least in extreme cases, such as the use of subliminal advertising to discourage smoking ${ }^{79}$ or visual illusions to encourage drivers to slow down. ${ }^{80}$

At the same time, the results of surveys may or may not track what would emerge from a sustained analysis of the normative questions, especially if the analysis is infused with an understanding of likely consequences. ${ }^{81}$ In fact, we do not know exactly what people are thinking when they respond to survey questions.

Consider an admittedly speculative hypothesis: System 1 prefers System 2 nudges. That is, people might well have a rapid, intuitive judgment that System 2 nudges are best. On this view, the automatic system favors System 2 nudges, and the deliberative system is necessary to override that form of favoritism. The reason might be that System 2 nudges seem the most respectful of individual agency. People might automatically think that it is best not to use a default rule or to frighten people, but instead to inform them, so that they can choose for themselves. But System 2 might be more consequentialist, and so it might not accept that automatic conclusion; it might ask about the actual effects of one or another nudge, and not place such an overriding emphasis on individual agency. ${ }^{82}$

76. Jung \& Mellers, supra note 33, at 68 .

77. On the United States, see SUNSTEIN, supra note 33, at 121-22. For European evidence, with broadly similar results, see generally Reisch \& Sunstein, supra note 74.

78. See SUNSTEIN, supra note 33, at 129-34.

79. Id. at 132 .

80. See Jung \& Mellers, supra note 33, at 66.

81. For a sustained argument in favor of "boosts," see generally Grüne-Yanoff \& Hertwig, supra note 24. Boosts can be seen as a subset of System 2 nudges. Riccardo Rebonato identifies nudges with System 1 and objects to them on both welfarist and nonwelfarist grounds. REBONATO, supra note 27 , at 6.

82. Cf. Joshua D. Greene, Beyond Point-and-Shoot Morality: Why Cognitive (Neuro)Science Matters for Ethics, 124 ETHICS 695, 700-01 (2014) (outlining evidence of automatic, System 1 
The data here are not sufficient to support the hypothesis that System 1 favors System 2 nudges (although I believe that it is true, at least for many respondents); the majority's preference for System 2 nudges may in fact be deliberative, rather than automatic. But the hypothesis that people make an automatic judgment in favor of System 2 nudges cannot be ruled out of bounds. It could easily be tested - for example, by asking people to answer survey questions under time pressure or after some kind of "cognitive load" (for example, a difficult math question, which would deplete analytical resources). It would be worthwhile to engage in such tests, to see whether many or most people do in fact show an immediate preference for System 2 nudges (as I suspect).

Consider another hypothesis: System 2 favors System 1 nudges. The basic idea is that System 2 will make all-things-considered judgments, with careful reference to consequences. Once reflection and deliberation are involved, people will often understand that System 1 nudges are both more effective and less costly, even if they lack intuitive appeal. ${ }^{83}$ The data here are also insufficient to support that hypothesis, though it is imaginable that a careful analysis of various situations would suggest that System 1 nudges often or generally work better. ${ }^{84}$ And as stated, the hypothesis is far too broad: in some circumstances, System 2 nudges will be better on normative grounds, and System 2 will acknowledge that fact. ${ }^{85}$

How should regulators think about the choice between the two kinds of nudges, having as they do a toolbox of instruments? It is possible, of course, that mandates will be better than nudges of any kind; perhaps they will be more effective and have higher net benefits. ${ }^{86}$

preference for deontological approaches, while contending that System 2 favors utilitarian approaches).

83. See Willis, supra note 37, at 431-32 (questioning the usefulness of financial education and arguing that helpful default rules are often better). Of course it is true that education can be helpful, and so System 2 might decide in its favor. See Grüne-Yanoff \& Hertwig, supra note 24, at 5 (arguing for boosting people's capacities).

84. See Bubb, supra note 29, at 1027-28 (arguing that System 1 nudges might well work better than System 2 nudges); Willis, supra note 37, at 431-32 (raising doubts about financial education and arguing for sensible default rules).

85. See generally Grüne-Yanoff \& Hertwig, supra note 24 (arguing for what they call boosts as opposed to what they call nudges).

86. For a provocative discussion, see generally SARAH CONLY, AGAINST AUTONOMY (2014) (arguing for coercive paternalism and rejecting autonomy-based objections). In the same vein, see Ryan Bubb \& Richard Pildes, How Behavioral Economics Trims Its Sails and Why, 127 HARV. L. REV. 1593, 1599 (2014) (defending mandates rather than nudges, with reference to behavioral findings). 
It is also possible that inaction is best, because any new intervention could have costs in excess of benefits. ${ }^{87}$ Economic incentives might be the best approach of all. ${ }^{88}$ But in many contexts, policymakers must specifically decide between System 1 nudges and System 2 nudges. ${ }^{89}$ To promote savings, they might engage in an educational campaign or opt for automatic enrollment $;{ }^{90}$ to promote access to public programs, they might rely on education or new default rules; to discourage smoking or distracted driving, they might rely on graphic warnings or a statistical presentation of some kind. How should policymakers decide?

To come to terms with that question, it would be helpful to specify the foundations for the answer. Suppose that we are welfarists, believing that any evaluation has to turn on the effects of an intervention on social welfare. ${ }^{91}$ If so, helpful questions are: What are the costs and benefits of a System 1 or System 2 nudge? ${ }^{92}$ Which has higher net benefits? For these questions, information about effectiveness is relevant, but it is hardly sufficient on its own. We need cost information as well. A maximally effective nudge might be too costly to be worthwhile, or it might have lower net benefits than a somewhat less effective but far less costly nudge.

In addition, the effectiveness information does not, by itself, give a full account of the benefits of a nudge. If 90 percent of people end up in savings plans, or if automatic enrollment in green energy cuts pollution by 20 percent, what exactly are the welfare consequences? Increases in participation rates and reductions in pollution seem desirable, but a great deal of further work would be necessary to understand exactly how desirable they are. Are increases in participation rates important? How important? What are the mortality and morbidity consequences of cutting pollution levels by 20 percent? In these respects, the survey questions, even in the various conditions,

87. See Edward L. Glaeser, Paternalism and Psychology, 73 U. CHI. L. REV. 133, 143-44, 148 (2006).

88. For a crisp discussion of the circumstances in which this is so, see STEPHEN BREYER, REGULATION AND ITS REFORM 48-49 (1981).

89. The First Amendment might turn out to be relevant insofar as government is compelling private speech. See Jolls, supra note 28 , at 54.

90. See Willis, supra note 37 , at 431 .

91. A welfarist approach is used in Bubb \& Pildes, supra note 86, at 1599, 1601 (suggesting that on welfare grounds, mandates are often preferable to nudges).

92. There might of course be a disjunction between welfare effects and what emerges from a cost-benefit analysis. I am bracketing that possibility here. For a discussion of the philosophical foundations of cost-benefit analysis, see generally MATTHEW D. ADLER, WELL-BEING AND FAIR DISTRIBUTION: BEYOND COST-BENEFIT ANALYSIS (2012). 
failed to provide respondents with full information. But it is noteworthy that as we have seen, even dramatically greater effectiveness from System 1 nudges failed to move a large group of people in its favor.

At first glance, welfarists would have no systematic reason to prefer System 1 nudges to System 2 nudges, or vice versa. Everything turns on the costs and benefits. ${ }^{93}$ But second-order considerations might cut in one direction or another. Part of the welfare calculation involves the cost of nudging itself. Under imaginable conditions, System 1 nudges can be far simpler to implement (as, for example, when they involve a mere default rule). ${ }^{94}$ At the same time, it is relevant to ask about the long-term effects of a nudge..$^{95}$ If a System 2 nudge would educate people and have beneficial effects in multiple domains of their lives, then it would have ancillary benefits, and these might turn out to be significant. ${ }^{96}$ (Consider financial education, which could benefit people when they are making many economic decisions, and which could, in principle, teach people statistical literacy as well. ${ }^{97}$ ) It is doubtful that survey responses, offered without extended contemplation, are adequately capturing these points, though some respondents might be attentive to them.

Suppose that we are not welfarists and that we believe that for reasons that involve dignity or autonomy, people ought to be active agents, affirmatively responsible for outcomes that affect their lives. ${ }^{98}$ To be sure, this idea has considerable ambiguity, but something of this sort undergirds the judgment that even if automatic enrollment of some kind can promote people's welfare, it is more respectful to them, and therefore best, for them to become informed and then to choose. ${ }^{99}$

93. If a System 1 nudge causes a welfare loss because people resent it, that loss would of course have to be included. $C f$. CONLY, supra note 86, at 155-59 (cataloguing the welfare effects of soda regulation).

94. See Willis, supra note 37 , at 432 (using a welfarist framework to challenge financial literacy training).

95. For relevant discussion, see Hunt Alcott \& Todd Rogers, The Short-Run and Long-Run Effects of Behavioral Interventions 18-22 (Nat'l Bureau of Econ. Research, Working Paper No. 18492, 2012), http://www.nber.org/papers/w18492 [https://perma.cc/9AAZ-6ZNB] (showing that information about social norms has only short-term effects unless the information is provided for a significant period of time, in which case it can have significant long-term effects).

96. See generally Grüne-Yanoff \& Hertwig, supra note 24 (defending "boosts").

97. See Gerd Gigerenzer, Risk SAVvy: How to MAKe GoOd DeCisions 246 (2015) (arguing for risk-related education).

98. See generally REBONATO, supra note 27 (arguing broadly on behalf of active choosing).

99. Cf. Nicolas Cornell, A Third Theory of Paternalism, 113 MiCH. L. REV. 1295, 1308 n.43, 1336 (2015) (arguing that paternalism shows such disrespect). 
Perhaps what is wrong with paternalism, even of the choice-preserving kind, is that it is insulting to people's capacity for agency; perhaps it shows a form of disrespect. ${ }^{100}$ Why not educate people, rather than enrolling them in a program that the government thinks is in their interest?

Different people who press this question might accept diverse kinds of answers. Some people might agree that if automatic enrollment is significantly better on welfare grounds, ${ }^{101}$ it is not necessary or preferable to educate people; but they would insist that the government must meet the burden of demonstrating that it is significantly better. Other people might adopt a strong presumption in favor of educative approaches and demand an exceptionally strong demonstration of higher net benefits. Still others might believe that, in at least some contexts, no such demonstration could justify a System 1 nudge. A continuum of beliefs might well be imagined. Such a continuum would, of course, fit with the results here.

\section{CONCLUSION}

In some circles, there is a strong preference for interventions that augment people's capacities, ${ }^{102}$ and skepticism about forms of choice architecture that seem to exploit or take advantage of people's fallibility. ${ }^{103}$ If a default rule works because of inertia, for example, it might be seen to be a form of manipulation, ${ }^{104}$ and even if that charge is far too strong, ${ }^{105}$ some people might contend that it is best to rely on education. ${ }^{106}$ On one view, the choice between System 1 and System 2

100. Id. A powerful response arguing that it is not disrespectful for government to act on the basis of an accurate understanding of people's capacities can be found in CONLY, supra note 86, at 36,45 .

101. Willis, supra note 37 , at 431-32 (urging that automatic enrollment is desirable and preferable to financial education).

102. See REBONATO, supra note 27, at 105 (arguing against nudges).

103. See generally Grüne-Yanoff \& Hertwig, supra note 24 (arguing for boosts rather than nudges). For relevant discussion from another direction, see generally CONLY, supra note 86 (defending coercive paternalism); Moles, supra note 34, at 2-4 (defending nudges against various objections).

104. On that topic, see Anne Barnhill, What Is Manipulation?, in MANIPULATION: THEORY \& PRACTICE 50, 71-72 (Christian Coons \& Michael Weber eds., 2014) (defining manipulation by reference to ideals for beliefs and emotions). Barnhill builds on Robert Noggle, Manipulative Actions: A Conceptual and Moral Analysis, 33 AM. PHIL. Q. 43, 46 (1996) (offering a similar definition).

105. For an argument that characterizing a default rule that works because of inertia (as manipulation) is far too strong, see generally SUNSTEIN, supra note 33.

106. See Grüne-Yanoff \& Hertwig, supra note 24, at 19. 
nudges depends on an assessment of comparative welfare effects, which requires a form of cost-benefit analysis. On another view, concerns about autonomy and dignity deserve a central place. ${ }^{107}$

My primary goal in this Article has been to investigate what people actually think about these questions. The central finding is that most people usually do prefer System 2 nudges, at least in the class of cases that were tested. Moreover, this preference cuts across partisan lines. When participants were told to assume that System 1 nudges were significantly more effective, they were more likely to prefer System 1 nudges - usually producing a shift toward such nudges of between 10 percent and 14 percent. ${ }^{108}$ When participants were given quantitative information showing that System 1 was significantly more effective, the shift was essentially identical (at least in a betweensubjects design). ${ }^{109}$ And when people were asked to assume that System 2 nudges were significantly more effective, their judgments were about the same as in the neutral condition - a most unexpected finding. ${ }^{110}$

Differences across partisan affiliations were not pervasive, but they did emerge in several contexts. For example, Democrats are more inclined to favor System 1 nudges in the contexts of green energy and water conservation. ${ }^{111}$ But the more dramatic finding is that in general, Democrats, Republicans, and independents show strikingly similar patterns of responses. They tend to favor System 2 nudges, at least in the standard cases, to shift by the same percentages both when they are asked to assume that the System 1 nudge is significantly more effective and when they are given quantitative information to demonstrate that it is more effective, and to show the same results in the neutral condition and when they are asked to assume that the System 2 nudge is significantly more effective. ${ }^{12}$

Follow-up studies show that in a within-subjects design, some of these findings are reversed. ${ }^{113}$ With that design, quantitative information that specifies the greater effectiveness of System 1 nudges does make a difference. With that design, a statement that System 2 nudges are "significantly more effective" increases support for System

107. See Waldron, supra note 35 (emphasizing the importance of dignity).

108. See supra Table 2.

109. See supra Table 3.

110. See supra Table 4.

111. See supra Table 5.

112. See supra Tables $6,7,8$.

113. See supra Table 15. 
2 nudges. A majority of respondents believes that System 1 nudges are likely to be more effective even when a majority prefers System 2 nudges - a strong clue that some people like those nudges for reasons that have nothing to do with effectiveness. Offered the opportunity to choose both System 1 and System 2 nudges, a large number of people do exactly that.

It is important to emphasize how much remains to be learned. As we have seen, different subject areas elicit different responses. If people care greatly about the end, perhaps effectiveness is all that matters, ${ }^{114}$ and the issue of agency will seem beside the point. For example, a System 1 nudge to reduce criminal violence might be preferred purely on effectiveness grounds, and people will not much care that a System 2 nudge preserves people's capacity to exercise their own agency (to murder or to rape). We can easily go further: if people are outraged by the conduct that is being targeted (murder, rape), and if they want to eliminate it, a mandate will be entirely acceptable, and a System 1 nudge, complementing that mandate, will be unobjectionable in principle.

To the extent that the issue is polarizing on political grounds, we might also expect to see polarized judgments about which kind of nudge to favor. The abortion example is exemplary on this ground. We have seen that while most Democrats and Republicans favor System 2 nudges to reduce abortions, the percentage of Republicans who favor System 1 nudges is significantly higher. For pollution reduction and water conservation, there is a similar difference, but in the opposite direction. If people question or do not like the ends of those who deploy nudges, they might end up preferring System 2 nudges, because they seem better on autonomy grounds. It should therefore be unsurprising that in some conditions, we also find partisan differences with respect to increasing voter registration and combatting childhood obesity.

These findings have large implications for judgments about nudging in general. They suggest that we will find comparative receptivity to System 1 nudges when the ends seem desirable and when people trust the officials who seek to secure them-and comparative

114. A focus on net benefits would of course be better than a focus on effectiveness, because welfare is what matters, and net benefits are a measure of welfare. See Cass R. Sunstein, Nudges That Fail 20 (July 18, 2016) (unpublished manuscript), http://papers.ssrn.com/sol3/papers.cfm? abstract_id=2809658 [https://perma.cc/CN97-CUUS] ("What matters is welfare, not effectiveness."). 
skepticism about System 1 nudges when the ends seem questionable or the officials untrustworthy. ${ }^{115}$

The most interesting question involves the precise tradeoff between sacrificing a degree of personal agency (as System 1 nudges might be taken to do) and increasing effectiveness. People put different weight on agency, and understand it in different ways, ${ }^{116}$ and some will demand a steep price, in terms of effectiveness, to compromise it. Here as well, context matters, and so the value placed on agency will be high for some populations (with respect to, say, the right to choose abortion), whereas it will be low for those very populations (with respect to, say, voter registration). The value of agency varies across persons and contexts.

Although some people greatly like to exercise agency, and want to retain it,${ }^{117}$ other people do not; they choose not to choose. ${ }^{118}$ On this count, context matters greatly. For some of the subjects of nudging, the exercise of agency is a cost rather than a benefit; voter registration is the most prominent case in point. A form of choice architecture that simply respects rights, and does not require people to take action to enjoy them, might be strongly favored on the ground that it makes things easy. ${ }^{119}$ The example suggests a larger point. System 1 might tend to prefer System 2 nudges, and System 2 might agree, but after sustained analysis, System 2 will often conclude that System 1 nudges are best.

115. Consider in this light the finding that as compared to people in other European nations, Hungarians are unusually skeptical about nudges. See Reisch \& Sunstein, supra note 74, at 14.

116. Note that both System 1 and System 2 nudges retain freedom of choice and so might be seen to respect agency. For a discussion, see Moles, supra note 34, at 17 (discussing autonomy and nudging).

117. For relevant evidence, see Bobadilla-Suarez et al., supra note 44, at 8,10-12 (finding that people will pay a premium to retain control, even when they know that delegation would be in their economic interest).

118. See generally SUNSTEIN, supra note 54 (discussing why the choice not to choose can be rational, and offering many examples of the phenomenon).

119. See THALER, supra note 3, at 237-38. 